\title{
Estimating Pore Space Hydrate Saturation Using Dissociation Gas Evolution Measurements: In Relevance to Laboratory Testing of Natural or Artificially Synthesised Hydrate-Bearing Soil Specimens
}

\author{
Anuruddhika G. Jayasinghe and Jocelyn L. H. Grozic \\ Department of Civil Engineering, Schulich School of Engineering, University of Calgary, 2500 University Drive NW, \\ Calgary, AB, Canada T2N 1N4 \\ Correspondence should be addressed to Jocelyn L. H. Grozic; jgrozic@ucalgary.ca
}

Received 4 August 2012; Revised 9 January 2013; Accepted 10 January 2013

Academic Editor: Umberta Tinivella

Copyright (C) 2013 A. G. Jayasinghe and J. L. H. Grozic. This is an open access article distributed under the Creative Commons Attribution License, which permits unrestricted use, distribution, and reproduction in any medium, provided the original work is properly cited.

\begin{abstract}
Physical properties of gas hydrate-bearing soils are known to be greatly affected by the pore space hydrate saturation. The accuracy of most saturation estimation methods is affected by hydrate growth habit and pore space distribution. We highlight the usefulness of dissociation gas evolution measurement (DGEM) method as a reference laboratory method to calibrate most other methods. The DGEM method is based on the concept of mass balance and properties of volume compatibility between two distinct states of a closed system. The accuracy of the estimation depends on (1) the precision with which the laboratory measurements of temperature, pressure, and volumetric properties are obtained (2) and the ability of theoretical models used in the calculation to closely represent the true nature of the system. We perform an analysis to evaluate the sensitivity of the estimation (1) to various laboratory measurements and (2) to the use of different theoretical models to generate a feel for the appropriateness of various assumptions associated with DGEM. The comprehensive guide to available resources useful in the hydrate saturation estimation also serves as one of the major contributions of the work presented.
\end{abstract}

\section{Introduction}

Gas clathrate hydrates (herein called "hydrate" or "hydrates") are nonstoichiometric compounds of water and low molecular weight hydrocarbons. Methane is the most common form of hydrocarbon found in natural hydrate systems. Hydrates are formed as a result of encapsulation of gas molecules within parent lattices of hydrogen bonded water molecules. Since the first discovery of naturally occurring gas hydrates in the Siberian Messoyakha gas field in 1960s [1], the investigations carried out over the decades have generated evidence for abundant existence of hydrates in marine sediments as well as in on shore permafrost regions where suitable pressure/temperature $(P / T)$ conditions exist in addition to sufficient methane flux. Of interest to this communication is the pore volume fraction of given sediment occupied by hydrate (termed hydrate saturation, $S_{H}$ ) and its quantification. The role of hydrate saturation in determining the host sediment behavior is explained followed by various techniques for determination of hydrate saturation. The dissociation gas evolution measurement (DGEM) method for hydrate saturation estimation is then presented as a reference method for calibrating and overcoming the challenges associated with most other methods. The discussion then proceeds to provide leads to sources of information which are required in the determination of input parameters to the DGEM method. The proceeding sensitivity analysis helps broadening our understanding as to the level of accuracy that we should be seeking in the laboratory and helps making appropriate assumptions as to the thermodynamic state of the soil-hydrate system. 


\section{Hydrate Saturation Dependency of Physical Properties of Host Sediments}

The presence (or more specifically the saturation) of hydrate within the pore space is known to alter the physical properties of host sediment to a great extent. The control of geomechanical (meaning: strength, deformation, and flow) properties of host sediments by hydrates has been a global research focus over the recent past and certainly is gaining more and more interest. The following presents a few experimental investigations of pore space hydrate to illustrate the important effects of hydrate saturation on the physical properties. Understanding of the effects of hydrate saturation highlights the importance of its accurate quantification.

When geomechanical properties of hydrate-bearing sediment are concerned, Ebinuma et al. [2], Hyodo et al. [35], Miyazaki et al. [6-9], and Masui et al. [10-12] display hydrate saturation dependency of stress-strain behavior including strength properties such as maximum deviatoric stress (or peak strength), Young's modulus at $50 \%$ of the stress at failure, cohesion, and dilation angle in drained triaxial compression tests. Ghiassian and Grozic [13] and Winters et al. $[14,15]$ illustrate the hydrate saturation dependency of stress-strain behavior and the excess pore pressure development compared to hydrate-free soil under undrained triaxial compression conditions. Yun et al. [16] illustrates the hydrate saturation dependency of stiffness and strength for Tetrahydrofuran (THF) hydrate under undrained conditions. Strain rate dependency of stress (under uniaxial compression) and creep behavior of hydrate-bearing sediments are investigated by Parameswaran et al. [17] for frozen specimens of THF hydrate. Cameron et al. [18] further the study of Parameswaran et al. [17] by including the temperature effects on the short- and long-term strength and deformation behavior. The exact effect of hydrate saturation on the strength and deformation behavior is detailed by Waite et al. [19]. The current communication does not wish to duplicate Waite et al. [19] discussion, but it wishes to highlight the impact of hydrate saturation on the soil properties to shed light on the importance of its accurate estimation.

Not only strength and deformation properties but also the flow properties of host sediments are altered by the presence of hydrate. According to Kneafsey et al. [20], Minagawa et al. [21], and Waite et al. [19], permeability of hydrated sediments is altered by both the degree of hydrate saturation and the pore scale hydrate distribution. Kumar et al. [22], and Liang et al. [23], and Ordonez et al. [24] are also among the researchers who relate hydrate saturation to host sediment flow properties.

In fact, most physical properties of hydrate-bearing sediments, not just geomechanical properties, are affected by the degree of hydrate saturation. These properties include acoustic wave speeds $[19,25-31]$, electrical properties (such as resistivity and dielectric constant) [32,33], and thermal properties (such as thermal conductivity) $[19,34,35]$. Hydrate saturation dependency of some of these properties has lead us to the development of several field and laboratory hydrate detection and quantification techniques. The effectiveness of these techniques greatly depends on pore space hydrate growth habit and effective medium models of such growth habits used in the interpretation of field or laboratory measurements. Those techniques based on acoustic and electrical properties and other methods of hydrate saturation estimation will later be discussed for effectiveness in comparison to the DGEM method which is the central focus for this communication. The following two sections outline our understanding of hydrate growth habit and its controls with the intention of facilitating the latter discussion of hydrate quantification methods.

2.1. Pore Space Hydrate Growth Habit. Presently, our understanding of porous media hydrate growth (although not extensive) is extensively limited to disseminated pore space hydrate growth within sediments of course granular particle assemblies of varying nature, other hydrate growth forms such as nodules, laminae, and growth within cracks and fissures particularly associated with fine grained sediments await proper attention. A number of studies including but not limited to those carried out by Kleinberg et al. [27], Murray et al. [36], and Winters et al. [31] agree upon the model developed by Helgerud [37] or similar effective medium models for pore space hydrate growth habit. Helgerud [37] approach is based on four distinct hydrate habit models for explaining soil hydrate interaction for unconsolidated packing of mineral grains. According to Helgerud [37], (1) hydrate forms preferentially at grain contacts, acting as cement between particles, (2) hydrate coats grains more or less uniformly, progressively cementing them as the hydrate volume increases, (3) hydrate grows in the interior of the pores as a part of the load bearing frame, and (4) hydrate grows without significant interaction with the frame as a pore filling substance. The hydrate habit models of Winters et al. [31] treat the hydrate formation at grain contacts and coating the grains within single cementation model.

The choice of effective medium models of hydrate growth habit in the quantification of hydrate saturation is an important decision with regard to certain hydrate saturation quantification methods. Hydrate saturations predicted by both Helgerud [37] and Winters et al. [31] are characteristic of speculated hydrate habit model. More recently, Chand et al. [25] developed a procedure to allow portion of hydrate saturation to be present as load bearing cement, while the remaining is treated as pore filling inclusions. The predicted hydrate saturations of this approach depend upon the accuracy with which the fraction of cementing hydrate is determined.

2.2. Controls on Pore Space Growth Habit. The fact that "little is known about the controls on growth habit" is brought to attention by Kleinberg et al. [27]. In fact, the growth habit could be determined by a complex interplay of variety of factors including "sediment mineralogy and texture, water salinity, other solutes such as biosurfactants, gas composition, and whether the hydrate form from free or dissolved gas," formation rate, and annealing effects [27]. For given sediment exposed to particular gas water chemistry, the pore scale hydrate distribution is most preferably governed by the formation procedure or more specifically, the sequential events during the formation stage. Apart from formation 
procedure, the preformation water saturation is the most deterministic factor of hydrate growth habit, and the fact is reflected in the experimental results of Howard et al. [26] and Minagawa et al. [21]. According to Howard et al. [26], the low initial water saturations result in acoustic wave velocities attributable to grain coating hydrate habit, while the high initial water saturations generate velocities attributable to hydrates acting as a part of the frame in a load bearing model.

\subsection{Techniques for Determination of the Hydrate Satura-} tion. The use of acoustic wave speed characteristics, electrical properties including resistivity and dielectric constant, chloride anomalies, and associated pore fluid conductivity, imaging methods, and DGEM are among the techniques for quantification of hydrate saturation. However, none of these techniques are without limitations, as it is only that some are relatively more effective than the others.

The studies of Priest et al. [28] and Waite et al. [30] are among the ample evidence found in the literature for hydrate saturation dependency of acoustic wave speeds. The acoustic properties, therefore, are used both in the field and laboratory estimations of pore space hydrate saturation. However, acoustic properties of hydrate-bearing sediments are, in fact, largely affected by the pore scale growth habit of hydrate $[19,26,27,29]$ as the shear stiffness of the medium is affected by the hydrate growth habit to a varying degree [19]. Winters et al. [31] and Chand et al. [25] use these phenomena in further analysis of determining growthhabit based hydrate saturation (forward model) or hydrate saturation-based growth habit (inverse model). Winters et al. [31] uses P wave measurements to investigate the hydrate growth habit of natural and laboratory synthesized hydratebearing specimen at varying hydrate saturations estimated with the use of collection and measurement of dissociation products. The results reflect upon the growth habit dependency of $\mathrm{P}$ wave measurements and the need for accurate independent estimate of hydrate saturation in correlating the acoustic wave speeds with hydrate growth habit. On the contrary, Chand et al. [25] develops an effective medium inversion algorithm for quantification of hydrate saturation which uses both $\mathrm{P}$ and $\mathrm{S}$ wave measurements. The degree of grain cementation (which is most certainly governed by many controlling factors including the preformation water saturation as discussed previously) is an input parameter to the algorithm. Neither studies provide evidence for capability of acoustic wave speed measurements as a stand-alone technology for hydrate saturation estimation; rather, it requires supporting technology to assess grain scale characteristics. Kleinberg et al. [27] also agrees that "acoustic properties of hydrate-affected sediments are very sensitive to the growth habit of hydrate". Howard et al. [26] also provides evidence for not only hydrate saturation but also growth habit dependency of acoustic wave speeds, while Priest et al. [28] highlights the need for validating current seismic models against experimental data obtained from laboratory synthesized hydratebearing sediment as the early attempts on such validations fail due to several reasons including the incapability of performing proper hydrate saturation quantifications. However, the limitations are not completely derived from growth habit related uncertainties. In fact, for an identified growth form, the effective use of acoustics in the hydrate saturation estimation relies on our understanding of the correlation between various sediment properties and stress state with wave speeds. "For naturally occurring hydrate-bearing sediments" "the $V_{\mathrm{p}} / V_{\mathrm{s}}$ ratio will be dependent on porosity, confining pressure and hydrate content and therefore quantification of hydrate pore saturation from either $V_{\mathrm{s}}, V_{\mathrm{p}}$, or $V_{\mathrm{p}} / V_{\mathrm{s}}$ ratios would be difficult without a detailed knowledge of sediment properties and stress state" [29].

The electrical properties can also be correlated to hydrate saturation and are therefore used in field and laboratory investigations. The study of Spangenberg and Kulenkampff [33] experimentally investigates methane hydrate saturation dependency of electrical properties of a glass bead sediment and comments on the difficulties associated with the applicability of the laboratory results in the field hydrate saturation predictions as the accuracy of such predictions depends on a combination of several factors including the cementing or noncementing grain scale habit of hydrate, grain size distribution, and grain shape distribution. Therefore, it is "advisable to use hydrate content estimations from electrical field measurements with caution as long as the used interpretation methods are not calibrated in the laboratory and verified for their applicability in a natural hydrate-bearing system" [33]. Further discussion on the limitations of the methods based on electrical resistivity is provided in Waite et al. [19].

Kilner and Grozic [32] employ the theory of dielectrics using the time domain reflectometry (TDR) technique and generate a clear correlation between dielectric constant and pore space hydrate saturation. They identify the need to isolate "the effects of individual variables such as: temperature, pressure, salinity, $\mathrm{pH}$, soil type (sands versus clays), grain size, density (porosity and permeability), and so forth." in generalizing such correlation for dielectrics and hydrate saturation. No evidence can be found in the literature for the use of TDR in field measurements; however, field application of the method is possible provided that the effects of aforementioned variables on the hydrate saturation measurement are known.

Chloride anomalies seem to generate accurate predictions of hydrate content for saline systems when employed in the laboratory under controlled conditions. The inapplicability of this method for systems without access to pore water during formation and for systems with zero salinity remains the disadvantage. Spangenberg et al. [38] estimates the hydrate saturation with the use of fluid resistivity measurements (or inferred fluid conductivity) combined with fluid conductivity salt concentration relations to estimate water conversion into hydrate during formation. Other input parameters include hydrate cage occupancy, hydrate density, and specimen pore volume. X-ray diffraction analysis of a portion of the specimen provides an independent estimate of hydrate saturation which is in good agreement with the former estimate.

Modern imaging technology such as X-ray computed tomography (CT) appears to be promising either as standalone technology for hydrate saturation estimation at the laboratory or as supporting technology to validate other methods such as those that specifically depend on the pore 
scale characteristics. Seol et al. [39] uses X-ray computed tomography observations of hydrated specimens to estimate hydrate saturation and other properties but with several assumptions. The assumptions are made in relation to hydrate cage occupancy, density of hydrate and gas phases, the host soil skeleton, and the degree of relative movement between the particles of the matrix in addition to the assumptions correlating X-ray attenuation and material mass. Density magnetic resonance (DMR) measurements are another approach to imaging hydrated sediments. Murray et al. [36] uses DMR measurements for hydrate saturation estimation in marine sediments and state that accurate estimations are generated conditioned by the use of modern wireline tools of certain specifications to acquire magnetic resonance data.

The DGEM method of hydrate saturation calculation is based on the principle of mass balance and the concept of volume compatibility between two distinct states of a closed system. The method is applicable in the laboratory for determination of hydrate saturation of natural cores or artificial hydrate-bearing specimens. The method involves obtaining pressure, volume, and temperature (PVT) data for a hydrate-bearing soil specimen within hydrate stability zone, then forcing the specimen to reach elevated temperatures and/or low pressures outsize hydrate stability zone resulting in hydrate dissociation, and then repeating PVT measurements allowing determination of phase composition of the system. The accuracy of the predictions relies on the precision with which the PVT data are obtained and the phase composition of system is determined under given state variables.

Despite the modern day technology, the use of "a variety of independent estimates of hydrate concentrations, such as resistivity logs, chloride anomalies, and gas evolution measurements (during hydrate dissociation)" combined "with acoustic data" results in "contradictory conclusions regarding the interaction between hydrate and the sediment" [28] and is an indication of poorly undertaken hydrate saturation estimates. The discrepancies between hydrate saturations estimated using various techniques are seemingly explained by the uncertainties in the estimated porosities and inaccurate parameter estimates used in corresponding analyses for at least electrical resistivity and $\mathrm{P}$ and $\mathrm{S}$ wave velocities [40]. Most methods for hydrate saturation estimation are affected by the properties such as following where the correlations between the measured parameter(s) and the properties are not clear to the scientific community to the date and/or the determination of the correlation requires employment of secondary measurements/supporting technology as follows:

(1) host sediment characteristics such as porosity, porosity distribution, geological features such as fractures and fracture orientation, intact properties of the soil grains, and stress state;

(2) pore space consistency (such as existence of free gas) and pore fluid characteristics (such as salinity and presence of other solutes);

(3) hydrate growth habit and distribution.
The challenges may be overcome by employing DGEM in the laboratory as a method of generating reference hydrate saturations in the process of validating saturations generated by other methods as it is associated with the following advantages:

(1) DGEM is based on fundamental physics and chemistry;

(2) the estimation depends only on the bulk hydrate filled pore volume fraction.

\section{Laboratory Testing of Artificial or Natural Hydrate-Bearing Specimens and Application of DGEM Method for Hydrate Saturation Estimation}

The following explains the typical experimental procedure for hydrate-bearing soil with application of DGEM method. The procedure is also illustrated in Figure 1 for hydrate formation in gas-rich environment.

Step 1. For laboratory synthesis of artificial methane hydratebearing specimens, this stage involves preparation of a soil specimen within which hydrates are to be artificially synthesized, assembly of the soil specimen within the testing system (which may be a triaxial soil testing apparatus, a portable cell for computer tomography or microscopic imaging, etc.), and application of $P / T$ conditions under which the hydrates are to be synthesized, as well as consolidation of the soil specimen.

For laboratory analysis of natural hydrate-bearing specimens, this stage involves assembly of the soil specimen within the testing system (which may be a triaxial soil testing apparatus, a portable cell for computer tomography or microscopic imaging, etc.), reestablishment of the field $P / T$ conditions under which the hydrates are stable, and consolidation of the soil specimen.

During this stage, measurements are performed to obtain initial specimen dimensions (height and diameter). For the case of laboratory synthesized hydrate specimens, the mass of dry soil occupying the specimen too is obtained. These measurements facilitate the estimation of the volume of void space $V_{V o}$ of the specimen. Any volume change of the specimen during consolidation is recorded, and $V_{V o}$ is corrected accordingly.

Step 2. For laboratory synthesis of artificial methane hydratebearing specimens, Step 2 involves hydrate formation within the soil specimen. Formation in water-rich environment generally involves continuous feed of methane (the hydrate former) dissolved water into the specimen. Formation in gas-rich environment generally involves continuous feed of methane into the partially water saturated specimen. It should be noted that there are other methods of hydrate synthesis at the laboratory which are associated with slightly different procedures. However, the completion of hydrate formation, if attempted in a water-rich environment, will result in two distinct phases: hydrate and gas dissolved water (1). As opposed to the aforementioned, hydrate formation, if attempted in a gas-rich environment, upon completion will 

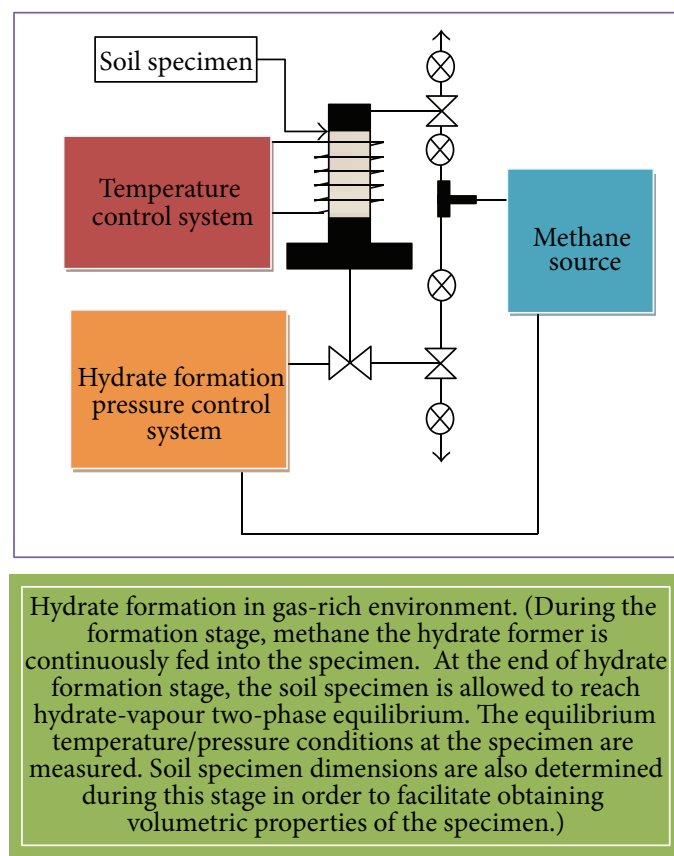
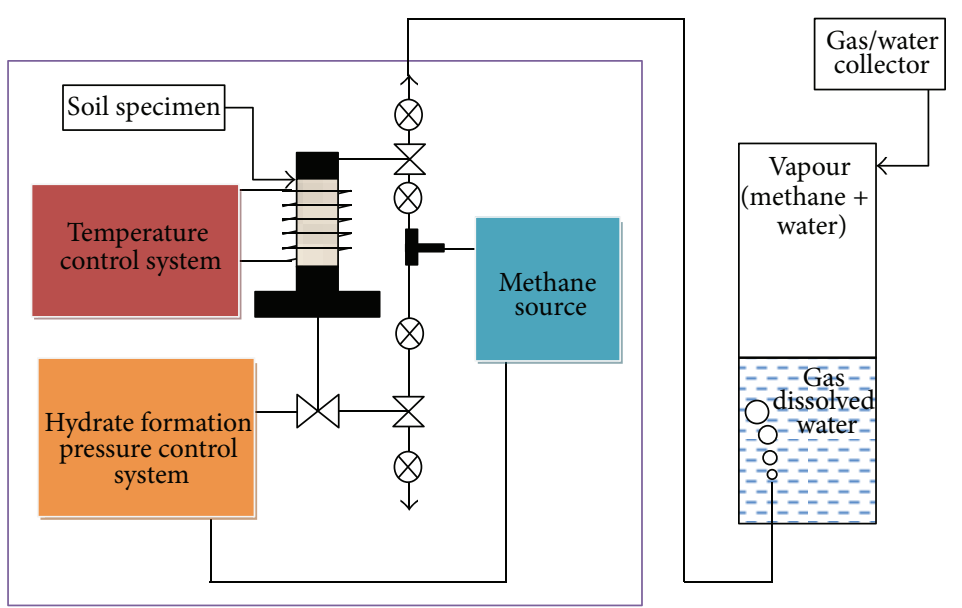

Hydrate dissociation. (During this stage, hydrate is allowed to dissociate by increasing the system temperature and/or reducing system pressure. The dissociation products are collected at the gas/water collector. During the collection process, all free gas present within the boundaries of the system is forced into the gas/water collector. The system is then allowed to reach aqueous liquid-vapour two-phase equilibrium.

The equilibrium temperature/pressure conditions of the system are measured. Volumetric measurements of gaseous and aqueous phases are also performed.)

Destructive or nondestructive

testing of the hydrated soil specimen

$\begin{array}{ll}\mathbf{1} \text { Three-way connecter } & \bigotimes \text { Two-way valve } \\ \bigotimes \text { Stop valve } & \longrightarrow \text { Fluid flow }\end{array}$

FIGURE 1: Hydrate formation in gas-rich environment, subsequent testing, and measurements to facilitate application of DGEM for hydrate saturation estimation.

result in two distinct phases: hydrate and vapour (2). In either case, incomplete formation will result in all three phases: hydrate, gas dissolved water, and vapour ((3), Figure 2) to be present in the system, while the system is assumed to be at a given temperature and a pressure within the hydrate stability zone where the actual temperature at a minute locality within the hydrate forming media can be approximated to the enforced temperature without significant loss of accuracy. The $P / T$ conditions of the system at the end of hydrate formation stage are herein after referred to as pre-dissociation temperature and pre-dissociation pressure. Equation (1) assumes that the soil specimen is at hydrateaqueous liquid ( $\mathrm{H}-\mathrm{Lw}$ ) two-phase equilibrium, while (2) assumes that the soil specimen is at hydrate-vapour (H-V) two phase equilibrium. The measured vales of pre-dissociation temperature and pressure are used to determine the methane concentration of different phases (i.e., $M_{H}, M_{W o}$, and $M_{G o}$ ) as detailed in Section 3.3.

Step 3. During this stage, the hydrated soil specimen may be subjected to a destructive test (e.g., a triaxial compression test) or a nondestructive test (e.g., acoustic, thermal, or flow property measurements, computer tomography, or electron scanning to generate hydrate distribution profiles). During such a testing procedure the soil specimen may or may not be allowed to undergo deformation and/or volume change.

Step 4. At the end of testing mentioned in Step 3, hydrates are allowed to dissociate, and the dissociation products are collected at a separate gas/water collector cell. Hydrate dissociation may be induced either by increasing the system temperature or by depressurization or by a combination of both. Dissociation of hydrates will result in two distinct phases to be present within the system: gas dissolved water, and vapour (Figure 2). Complete collection of any gas trapped within the host sediment at the gas/water collector is ensured by flooding the soil specimen with water. The system including the host soil specimen, gas/water collector, and the connection tubing in- between is then allowed to reach $\mathrm{H}-\mathrm{Lw}$ two phase equilibrium under $P / T$ conditions outside hydrate stability zone. These $P / T$ conditions of the system are referred to as post-dissociation conditions hereinafter and are usually represented by the ambient room temperature and moderate to low pressures. The measured values of post-dissociation temperature and pressure are used to determine the methane concentration of different phases (i.e., $M_{W f}$ and $M_{G f}$ ) as detailed in Section 3.3. Other laboratory measurements associated with this stage are used to determine the volumetric 


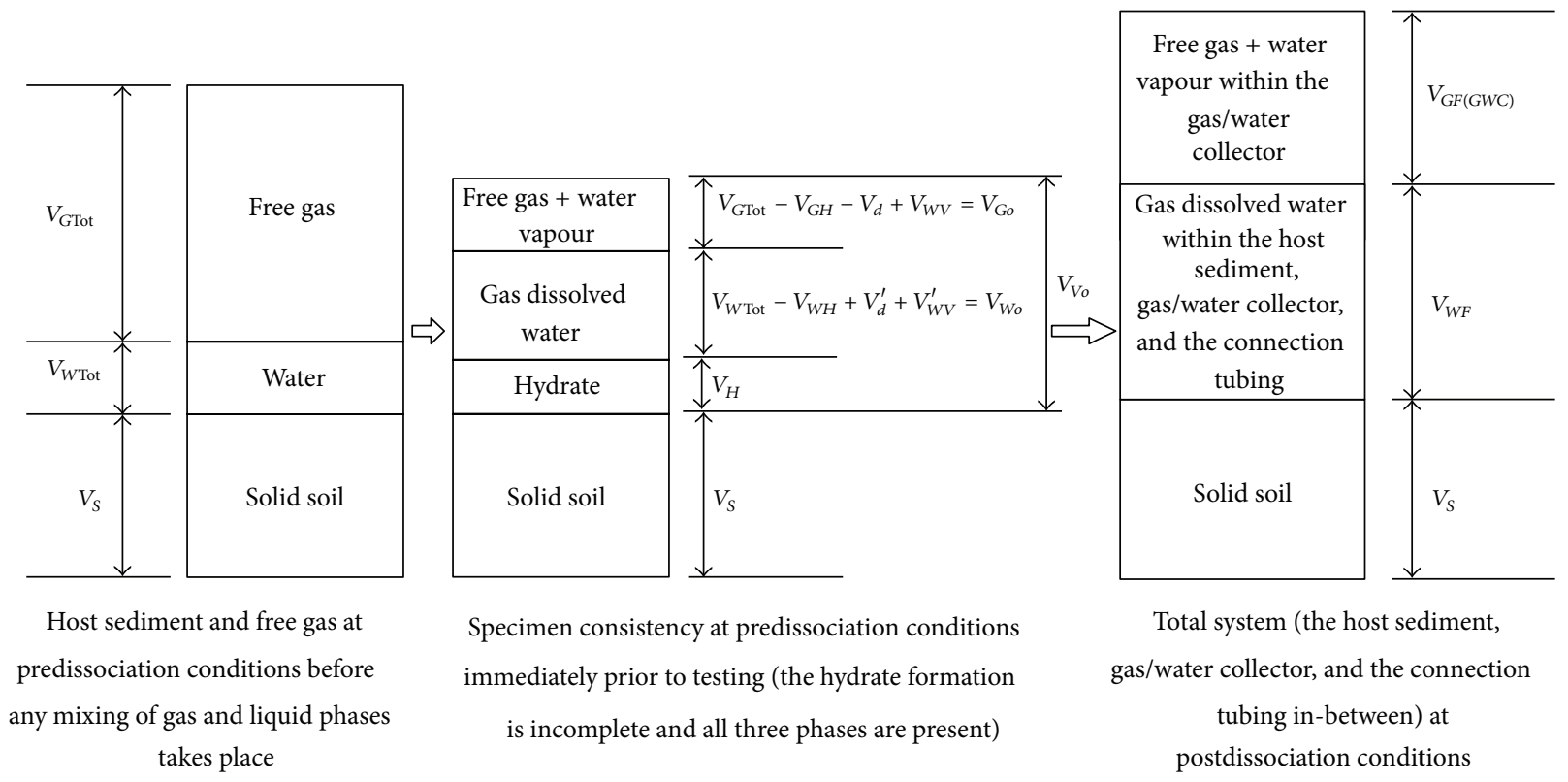

FIGURE 2: System consistency at pre-and post-dissociation conditions.

parameters including $V_{G f(G W C)}, V_{\text {ext }}, V_{W T o t}$, and $V_{G i(G W C)}$, and the details are presented in Section 3.2.

The principle of mass balance when applied between the pre-and post-dissociation conditions of the system appear in following forms for (1) complete formation in water-rich environment, (2) complete formation in gas-rich environment, and (3) incomplete formation in either water-or gasrich environments:

$$
\begin{gathered}
M_{H} V_{H}+M_{W o} V_{W o}=M_{W f} V_{W f}+M_{G f} V_{G f}, \\
M_{H} V_{H}+M_{G o} V_{G o}=M_{W f} V_{W f}+M_{G f} V_{G f}, \\
M_{H} V_{H}+M_{W o} V_{W o}+M_{G o} V_{G o}=M_{W f} V_{W f}+M_{G f} V_{G f} .
\end{gathered}
$$

The mass balance equations when coupled with volume compatibility equations derived from Figure 2 results in the following relationships for the hydrate saturation, respectively:

$$
\begin{gathered}
V_{H}=\frac{V_{G f} M_{G f}-V_{V o} M_{W o}+V_{W f} M_{W f}}{\left(M_{H}-M_{W o}\right)} \\
V_{H}=\frac{V_{G f} M_{G f}-V_{V o} M_{G o}+V_{W f} M_{W f}}{\left(M_{H}-M_{G o}\right)} \\
V_{H}=\frac{V_{G f} M_{G f}-V_{V o} M_{G o}+V_{W f} M_{W f}-V_{W T o t}\left(M_{W o}-M_{G o}\right)}{\left(M_{H}-M_{G o}\right)-V_{l} / V_{e}\left(M_{W o}-M_{G o}\right)} .
\end{gathered}
$$

The following subsections discuss measurements and estimates that are required to be performed in the hydrate saturation estimation in order to obtain the volume and methane concentration (or density) components that appear in (4)-(6). It should be noted that methane-water binary system has been considered hereinafter for the presentation of DGEM for hydrate saturation estimation. The intension is to provide the reader with an understanding of the system at pre-and post-dissociation conditions and with a guide to sources of information available in the literature allowing proper calculations of the properties of each phase of the system. The challenges associated with each measurement or parameter estimation are also discussed.

3.1. Measured Parameters. The measured parameters include the direct measurements of $P / T$ state variables for system at pre-and postdissociation conditions and are used in conjunction with estimates of methane density in the hydrate saturation calculation. These parameters include the following:

(1) pre-dissociation temperature;

(2) pre-dissociation pressure (gauge);

(3) post-dissociation temperature: if the system is allowed to reach thermodynamic equilibrium with the room conditions, the post-dissociation temperature is the same as ambient room temperature. However, ensuring the system reaches thermodynamic equilibrium with the environment or within the two-phase aqueous liquid-vapour (Lw-V) system itself is a matter of extreme practical difficulty. This issue is later discussed in more detail with relevance to estimation of total aqueous phase volume of the system $V_{W f}$ at post dissociation conditions;

(4) post-dissociation pressure (gauge)

(5) ambient room temperature

(6) ambient pressure: the ambient pressure is used coupled with gauge pressure measurements in arriving at system state variables under pre-and post dissociation conditions, and can be obtained using 
an absolute pressure transducer. Alternatively, local weather reports may be used to obtain this parameter. Ambient pressure is mentioned as one of the top two contributors to error in hydrate saturation calculation by Lee and Collett [40] with respect to their gas evolution measurements of pressure cores.

3.2. Estimates of Volumetric Parameters. The volumetric parameters are derived from multiple laboratory measurements performed during a typical test and are used as inputs with (4), (5), and (6) in the hydrate saturation estimation. These parameters include the following:

(1) Volume of voids $V_{V o}$ within the hydrated host sediment under pre-dissociation conditions immediately prior to testing as mentioned in Step 3 of Section 3 is usually estimated with specimen dimensions (height and diameter), grain density of soil, and mass of dry soil occupying the specimen. The $V_{V o}$ for a laboratory synthesized hydrate specimen is corrected for any specimen volume changes occurring due to consolidation and so forth between the time of measurement of specimen dimensions and reaching the pretest conditions within the hydrate stability zone.

(2) Total gas phase volume $V_{G f(G W C)}$ of the system at completion of the collection of gas/water products from hydrate dissociation is usually estimated with height and diameter of a gas column of a gas/water collection assembly.

(3) Total volume of hydrate forming gas-filled elements external to the immediate boundaries of the specimen $V_{\text {ext }}$ for which the material mass present within is forced into the gas/water collector during collection of dissociation products is next. The method of estimating such volume component needs to be given proper attention during planning of experimental procedure. For the tests carried out at the Geotechnical Gas Hydrate Research Laboratory (GGHRL) at the University of Calgary, the gas volume associated with material mass external to the specimen boundaries arise only from the quantity of gas present within the specimen end caps and connection tubing between the specimen top cap and the gas/water collector. This quantity is carefully determined from mass of water occupying the corresponding volume at full water saturation, density of water, ambient temperature, and pressure.

(4) Total aqueous phase volume $V_{W f}$ of the system under post-dissociation conditions (which includes the soil specimen, gas/water collector, and the connection tubing in between) at completion of collection of gas/water products from hydrate dissociation follows. Theoretically, $V_{W f}$ is the initial volume of water present within the system corrected for $P / T$ differences between the initial and post-dissociation conditions plus the total inflow minus the total outflow. The previous quantity is given by the net summation of the following components: (1) the volume of water available at pre-dissociation conditions immediately prior to testing corrected for $P / T$ differences between the pre-and post-dissociation conditions; (2) volume of water generated from hydrate dissociation calculated at post-dissociation $P / T$ conditions; (3) volume inflow in to the specimen (if any) during the collection of dissociation products at the gas/water collector; (4) volume of water initially present within connection tubing (if any) between the specimen and the gas/water collector corrected for $P / T$ differences between initial and post-dissociation conditions; (5) volume of water initially present within the gas/water collector corrected for $P / T$ differences between initial and post-dissociation conditions; (6) volume of water displaced from gas/water collector (if any) during collection of dissociation products. The component (6) is valid only in the case of a water displacement column type collector with the assumption that displaced water would not carry away significant quantity of hydrate forming gas (methane) in dissolved form. The fact that methane dissolves in water at very slow rates at neat ambient conditions especially when no significant agitation of the aqueous liquid body is present may even lead to difficulties in justifying the efforts needed to estimate $V_{W f}$ under practical circumstances. Further, such a system cannot be expected to reach thermodynamic $\mathrm{Lw}-\mathrm{V}$ equilibrium within a reasonable time span for any efforts of quantification to be justifiable. Therefore, $V_{W f}$ may be abandoned from the hydrate saturation calculation.

(5) Initial volume of water $V_{W T o t}$ available for hydrate formation is ideologically estimated at pre-dissociation or hydrate forming $P / T$ conditions before substantial or preferably any mixing of water and hydrate forming gas takes place. For laboratory synthesized hydrate, this quantity can be estimated from initial soil moisture content or from water saturated specimen pore volume minus displaced pore water volume associated with gas introduction (corrected for $P / T$ differences between initial and pre-dissociation conditions). Estimation of this quantity is needed only when the complete formation of hydrate cannot be guaranteed under pre-dissociation conditions immediately prior to testing. Determining this quantity for natural hydrate-bearing specimens of core samples could be extremely challenging; instead, it would be more practical to determine the specimen consistency at pre-dissociation conditions immediately prior to testing. Lee and Collett [40] address the issues with determining the specimen consistency. Seemingly, Lee and Collett [40] assume that the specimen pore space is completely occupied by hydrate and free water neglecting the possible presence of free gas within the specimen.

(6) Initial gas phase volume $V_{G i(G W C)}$ at the gas/water collector follows. Absence or presence of such volume component depends on the design of the gas/water 
collector: (1) if the gas/water collector is designed in the form of a water displacement column with no initial air/gas within, no such volume component exists; (2) if the gas/water collector is designed in the form of a pressure vessel with no flow out during collection of dissociation products, an initial gas volume of $V_{G i(G W C)}$ may present within the collector. In the latter case the initial gas volume component may be determined with the use of height and diameter of the gas column. The hydrate saturation calculation presented herein considers no existence of initial gas volume within the collector.

\subsection{Estimates of Methane Density and Volume of Hydrate} Bond Water. Estimates of methane density and volume of hydrate bond water are required as inputs with the use of (4), (5), or (6) in the hydrate saturation estimation. The following outlines the methods for estimating five different methane density values at various $P / T$ conditions in and out the hydrate stability zone of methane-water binary system. Various thermodynamic and empirical models are assumed for the methane-water binary system in the estimation of these parameters. In addition to the density parameters, the molar volumes of water in the aqueous liquid $\left(V_{l}\right)$ and hydrate $\left(V_{e}\right)$ phases are estimated.

(1) The molar volume of water $V_{l}$ is determined either at post-dissociation $T$ and $P$ or at pre-dissociation $T$ and $P$ with the use of water density obtained from Lide [48] and molar mass of water. This quantity is used in the hydrate content calculation to estimate the volume of water generated as a dissociation product or consumed during hydrate formation $V_{W H}$ which is estimated with the following relationship:

$$
V_{W H}=V_{l} \frac{V_{H}}{V_{e}} .
$$

If the volume of hydrate bond water $V_{W H}$ is used in the hydrate saturation calculation with relevance to the system consistency at post-dissociation conditions, the postdissociation $T$ and $P$ will be applicable to $V_{l}$. Otherwise, predissociation $T$ and $P$ should be used.

(2) Molar volume of water in the hydrate lattice $V_{e}$. is used as a secondary input in the estimation of methane density in the hydrate phase. The volume of hydrate lattice per mole of water at pre-dissociation $T$ and $P$ (or the molar volume of water in the hydrate phase) $V_{e}$ is determined considering the hydrate lattice geometry. The fitted model of Hester et al. [49] expresses the lattice parameter as a function of temperature:

$$
\frac{a-a_{o}}{a_{o}}=\exp \left(\begin{array}{c}
a_{1}\left[T-T_{o}\right] \\
+\frac{a_{2}}{2}\left[T-T_{o}\right]^{2} \\
+\frac{a_{3}}{3}\left[T-T_{o}\right]^{3}
\end{array}\right)-1
$$

where $a_{o}$ is the lattice parameter at a reference temperature $T_{o}$.

At a reference temperature of $298.15 \mathrm{~K}$, it is shown that all hydrates of a given structure can be fitted using the previous expression. For structure I hydrates, the model constants $a_{1}=$ $1.1280 E-04, a_{2} / 2=1.8003 E-07$, and $a_{3} / 3=-1.5898 E-11$. The only guest dependent parameter $a_{o}(\AA)$ at $298.15 \mathrm{~K}$ could be extrapolated with adequate accuracy using the relationship developed by Ogienko et al. [50] for the temperature range of 86-267 K for cubic structure I methane hydrate. Consider

$$
a_{o}=\left(\begin{array}{c}
11.835(11)-1.12(116) \times 10^{-4} T_{o} \\
+2.47(56) \times 10^{-6} T_{o}{ }^{2}
\end{array}\right) .
$$

The molar volume of water in the hydrate phase $V_{e}$ is then determined as follows for a structure I unit cell of 46 water molecules:

$$
V_{e}=\frac{a^{3} \times\left(6.02214179 \times 10^{23} \mathrm{~mol}^{-1}\right)}{46} .
$$

The model developed by Hester et al. [49] fits significantly well with the experimental data of Shpakov et al. [51] and those of Ogienko et al. [50]. Shpakov et al. [51] also presents a prediction model for $V_{e}$ however, the predictions appear to deviate from their experimental results as the temperature increases. Alternatively, Sun and Duan [52] present an equation (11) for the determination of $V_{e}$ as a function of $T$ and $P$, although the origin and the particulars of derivation of the expression are not clear. Consider

$$
\begin{aligned}
V_{e}(T, P)=[11.820+ & 2.217 \times 10^{-5} T \\
+ & \left.2.242 \times 10^{-6} T^{2}\right] \frac{10^{-30} N_{A}}{N_{W}} \\
\times & \exp \left[-3.5 \times 10^{-4}(P-0.1)\right. \\
& \left.+7.07 \times 10^{-6}(P-0.1)^{1.5}\right] .
\end{aligned}
$$

(3) The hydrate number $n_{k}$ and methane concentration in the hydrate phase $M_{H}$ are next. The maximum amount of methane that can occur in methane hydrate is fixed by the clathrate geometry. Most commonly, methane forms hydrates of molecular structure called Structure I. The cubic unit cell of structure I hydrate consists of 46 water molecules forming 2 small cavities and 6 large cavities. When all cavities are occupied by methane the composition is $\mathrm{CH}_{4} \cdot 5.75 \mathrm{H}_{2} \mathrm{O}$ where 5.75 is referred to as the hydrate number, $n_{k}$. However, gas clathrate hydrates are known to be nonstoichiometric compounds and are stable at range of values of hydrate numbers [53]. In fact, different cage occupancies are obtained at different formation temperatures and pressures $[43,52,54$, $55]$ and at different overall methane compositions $[53,56]$. According to the predictions of Sun and Duan [52], "the occupancy fraction of methane both in small cage and large cage increases with increasing temperature and pressure at" H-Lw "equilibrium." Table 1 summarises hydrate numbers generated by a number of independent experimental studies by Galloway et al. [47], Handa [41], Handa and Stupin [42], Sum et al. [43], Uchida et al. [44], Seo et al. [45], and Circone et al. [46]. Fair amount of variability can be identified as associated with the experimentally derived values of $n_{k}$, and correlating hydrate number with formation conditions does 
TABLE 1: References for experimental determination of hydrate number, $n_{k}$.

\begin{tabular}{|c|c|c|c|}
\hline Reference & Temperature/pressure conditions & Hydrate number & Remarks \\
\hline Handa, 1986 [41] & $\begin{array}{c}253.0 \pm 0.5 \mathrm{~K} \\
3.40 \pm 0.10 \mathrm{Mpa}\end{array}$ & 6.00 & $\begin{array}{l}\text { Determines hydrate number for bulk hydrate using } \\
\text { gas evolution measurements upon dissociation }\end{array}$ \\
\hline $\begin{array}{l}\text { Handa and Stupin, } 1992 \\
\text { [42] }\end{array}$ & $\begin{array}{l}263.0-276.2 \mathrm{~K} \\
2.64-5.26 \mathrm{Mpa}\end{array}$ & 5.94 & $\begin{array}{l}\text { Determines hydrate number for hydrate formed } \\
\text { within } 70 \text { A silica gel-pores }\end{array}$ \\
\hline Sum et al., 1997 [43] & $\begin{array}{l}273.65-276.65 \mathrm{~K} \\
\text { at corresponding three phase } \\
\text { equilibrium pressure }\end{array}$ & $6.04 \pm 0.03$ & $\begin{array}{l}\text { Determines the hydrate number over a range of } \\
\text { temperatures for bulk hydrate at corresponding three } \\
\text { phase equilibrium pressure }\end{array}$ \\
\hline Uchida et al., 1999 [44] & $\begin{array}{c}273.2-278.4 \mathrm{~K} \\
3.0-7.0 \mathrm{Mpa}\end{array}$ & $6.2 \pm 0.2$ & $\begin{array}{l}\text { Determines the hydrate number for bulk hydrate } \\
\text { over a range of temperatures and pressures }\end{array}$ \\
\hline Seo et al., 2002 [45] & $\begin{array}{l}274.15 \mathrm{~K} \\
10.0 \mathrm{Mpa}\end{array}$ & 6.00 & $\begin{array}{l}\text { Determines the hydrate number for bulk hydrate at } \\
\text { the given temperature and pressure }\end{array}$ \\
\hline Circone et al., 2005 [46] & $\begin{array}{c}263-285 \mathrm{~K} \\
1.9-9.7 \mathrm{Mpa}\end{array}$ & $5.99 \pm 0.07$ & $\begin{array}{l}\text { Determines an average hydrate number along the } \\
\text { three-phase equilibrium boundary for bulk methane } \\
\text { hydrate using gas evolution measurements upon } \\
\text { dissociation over a range of temperatures and } \\
\text { pressures }\end{array}$ \\
\hline Galloway et al., 1970 [47] & $\begin{array}{c}283-288.5 \mathrm{~K} \\
7.10-13.17 \mathrm{Mpa}\end{array}$ & $5.84-6.34$ & $\begin{array}{l}\text { Determines the hydrate number with } \pm 15.6 \% \text { average } \\
\text { maximum relative uncertainty over a range of } \\
\text { temperatures and pressures }\end{array}$ \\
\hline
\end{tabular}

not appear to be possible with the limited experimental data. Alternatively, the model of Sun and Duan [52] allows computing the hydrate cage occupancy at given $P / T$ conditions over the H-Lw region. The CSMGem calculator of Colorado School of Mines (originally developed by Ballard, [57]) also proves to be a useful tool in generating small and large cage occupancies under $\mathrm{H}-\mathrm{V}$, hydrate-aqueous liquid-vapour $(\mathrm{H}$ $\mathrm{Lw}-\mathrm{V}$ ) and $\mathrm{H}$-Lw equilibrium conditions for a given system at known $P / T$ allowing subsequent calculation of $n_{k}$. However, commenting on the relative accuracy of the predictions of Sun and Duan [52] and CSMGem is beyond the scope of this communication. The hydrate number $n_{k}$ is used in the hydrate saturation calculation to determine the methane concentration in the hydrate phase under pre-dissociation conditions. The moles of methane in the hydrate phase under pre-dissociation conditions are determined using the following relationship with the approximated or estimated $n_{k}$ as an input variable:

$$
M_{H}=\left(\frac{1}{n_{k}}\right)\left(\frac{1}{V_{e}}\right)
$$

(4) Vapour phase methane concentration under $(\mathrm{H}-\mathrm{V})$ equilibrium $M_{G o}$ follows. Determination of vapour phase methane concentration within the $\mathrm{H}-\mathrm{V}$ region of $\mathrm{CH}_{4}-\mathrm{H}_{2} \mathrm{O}$ system requires computation of vapour phase composition (i.e., mole fraction of methane) and the molar volume of the vapour at given $P / T$ conditions. The equilibrium vapour phase composition can be derived from the moisture content measurements in methane in the presence of hydrate performed by Chapoy et al. [58, 59], Folas et al. [60], Løkken et al. [61], Kosyakov et al. [62], Oellrich and Althause [63], Youssef et al. [64], Aoyagi et al. [65], Aoyagi et al. [66], Sloan et al. [67], Song et al. [68], and Zhang et al. [69]. The moisture content data range over $P / T$ regions of $3.4-10.4 \mathrm{MPa}$ and $240-280 \mathrm{~K}$. Moisture content data is usually presented in the literature in terms of ppm (parts per million or more specifically the number of moles of methane present per million moles of the methane-water mixture) $[59,64]$ or in terms of lbm/MMCF (pound mass per million cubic feet) at a reference pressure and a temperature (which are usually 14.7 psia and $60^{\circ} \mathrm{F}$ ). Using the aforementioned in the calculation of methane concentration per unit volume of vapour phase requires the use of an appropriate Equation of State (EoS) capable of generating the molar volume of vapour phase at the corresponding pre-dissociation $P / T$ conditions at which the test is conducted and at the reference $P / T$ conditions $\left(60^{\circ} \mathrm{F}\right.$ and 14.7 psia). Many of the equations of state for methanewater system are applicable over the Lw-V region but not in the presence of hydrate. Duan et al. [70] provides a hint of the difficulties associated with accommodating the complex volumetric and phase behaviour in the presence of hydrates in to the formulation of an EoS. Therefore, the methane concentration in vapour phase needs to be calculated by approximating an existing pure component EoS. As such we recommend the use of the pure component EoS for methane developed by Duan et al. [71] in the determination of $M_{G o}$. Alternatively, the CSMGem calculator can also be used to determine $M_{G o}$. The vapour phase methane concentration is thus calculated by approximating $M V_{V\left(\mathrm{CH}_{4}+\mathrm{H}_{2} \mathrm{O}\right) @(\mathrm{H}-\mathrm{V})}$ with pure component (methane) molar volume under hydrate forming conditions as follows:

$$
M_{\mathrm{Go}}=\frac{y_{\mathrm{CH}_{4}}}{M V_{V\left(\mathrm{CH}_{4}+\mathrm{H}_{2} \mathrm{O}\right) @(\mathrm{H}-\mathrm{V})}} .
$$

(5) Aqueous phase methane concentration under ( $\mathrm{H}$ Lw) equilibrium $M_{W o}$ follows. Methane solubility in water in 
equilibrium with its hydrate has been researched by many [52, 72-76]. In the absence of hydrate methane solubility increases with decreasing temperature and increasing pressure however, in the presence of hydrate the solubility decreases with decreasing temperature and increasing pressure [74-76]. The peak in the hydrate solubility corresponds to the three phase $\mathrm{H}$-Lw-V equilibrium temperature at a given pressure [76]. The pressure dependency of the solubility profile could be considered insignificant in the presence of hydrates [72]. However, according to Lu et al. [74], the pressure effect on solubility in the presence of hydrate is small at low temperatures than at high temperatures; also, the relative change in solubility over the same magnitude of pressure change increases with pressure. The model developed by Zatsepina and Buffett [76] investigates the effects of temperature, pressure, and salinity on methane solubility. However, "the model of Zatsepina and Buffett $[76,77]$ underestimated $\mathrm{CH}_{4}$ solubility in water and underestimated the salting-out effect of electrolyte on $\mathrm{CH}_{4}$ solubility both at" aqueous liquid-vapour (Lw-V) "equilibrium and at" H-Lw "equilibrium" [52]. Davie et al. [72] fits theoretical calculations of Zatsepina and Buffett [76] with a simple equation. Hashemi et al. [73] presents an improved model to predict solubilities in pure water at $\mathrm{H}-\mathrm{Lw}$ and $\mathrm{H}-\mathrm{Lw}-\mathrm{V}$ equilibrium. The results closely match the experimentally derived values of Servio and Englezos [75]. The effects of capillarity and salinity are also taken into account in the predictions of the model Sun and Duan [52]. The model requires temperature, pressure, salinity, and pore radios as the inputs. It is noteworthy that the pore radios effects are negligible for coarse grained sediments, and the aforementioned fact is visible in the model predictions for radii greater than $300 \mathrm{~nm}$. The model results over the $\mathrm{H}-\mathrm{Lw}$ region and along the $\mathrm{H}-\mathrm{Lw}-\mathrm{V}$ boundary have been verified against experimental data of Servio and Englezos [75], Kim et al. [78], and Seo et al. [45] for solubility in pure water. Lu et al. [74] using Raman spectroscopy measures methane concentrations in pure water in equilibrium with structure I hydrate. A relationship for mole fraction $x_{\mathrm{CH}_{4}}$ of methane in water is derived as a function of temperature ( $T$ in $\mathrm{K})$ and pressure $(P$ in $\mathrm{MPa})$ :

$$
x_{\mathrm{CH}_{4}}=\exp \left(\begin{array}{c}
11.0464+0.023267 P \\
-(4886.0+8.0158 P) / T
\end{array}\right) .
$$

The predictions obtained using (14) are in good agreement with the measured values given by Servio and Englezos [75] and values predicted by Sun and Duan [52]. Determination of aqueous phase methane concentration requires the knowledge of aqueous phase molar volume at the given $P / T$ in addition to methane solubility (i.e., mole fraction). The CSMGem calculator proves to be a useful tool as it is capable of generating both the methane mole fraction and the molar volume of aqueous phase, and thus $M_{W o}$ can be calculated as follows:

$$
M_{W o}=\frac{x_{\mathrm{CH}_{4}}}{M V_{\mathrm{LW}\left(\mathrm{CH}_{4}+\mathrm{H}_{2} \mathrm{O}\right) @(\mathrm{H}-\mathrm{Lw})}} .
$$

The aqueous phase methane concentration under $\mathrm{H}$-Lw equilibrium is not included in the subsequent sensitivity analysis as the sensitivity analysis is carried out for hydrates formed within gas-rich environment.

(6) Aqueous phase methane concentration under (LwV) equilibrium $M_{W f}$ is next. Both experimental studies and mathematical derivations for methane solubility in water in the absence of hydrate phase could be cited in the literature [52, 73, 79-87]. Hashemi et al. [73] predicts solubilities in pure water at $\mathrm{Lw}-\mathrm{V}$ equilibrium in addition to that at $\mathrm{H}-\mathrm{Lw}$ and $\mathrm{H}-\mathrm{Lw}-\mathrm{V}$ equilibrium. The predictions are verified against experimental values presented by Servio and Englezos [75]. The model developed by Duan et al. [82] predicts methane solubility for a system at a given temperature/pressure/salinity condition, and the results are verified against experimental results of Claussen and Polglase [81], O'Sullivan and Smith [83], Sultanov et al. [85], BenNaim and Yaacobi [80], Yamamoto et al. [87], Price [84], and Wiesenburg and Guinasso [86]. However, introducing a more recent model with better accuracy Duan and Mao [79] affirms that "all of the published models, including the Duan model [82], are found to posses intolerable deficiencies." Duan and Mao [79] model is capable of predicting the liquid phase density $(\mathrm{g} / \mathrm{cc})$ in addition to methane solubility in terms of molality allowing the calculation of the number of moles of methane present per unit volume of liquid. The model presented by Sun and Duan [52] could also be used to generate more accurate predictions provided that the temperature, pressure, salinity, and pore radios are known. The predictions over the Lw-V region have been verified for solubility in pure water against data of Servio and Englezos [75], Kim et al. [78], and Seo et al. [45]. The model of Chapoy et al. [88] can also be used to generate accurate aqueous phase methane mole fractions over the temperature range of 275$313 \mathrm{~K}$ and pressures up to $18 \mathrm{MPa}$. Alternatively, the CSMGem calculator is also capable of generating both the methane mole fraction and the molar volume of aqueous phase. $M_{W f}$ can thus be determined as follows with a suitable choice of aforementioned mathematical models:

$$
M_{W f}=\frac{x_{\mathrm{CH}_{4}}}{M V_{\mathrm{Lw}\left(\mathrm{CH}_{4}+\mathrm{H}_{2} \mathrm{O}\right) @(\mathrm{Lw}-\mathrm{V})}} .
$$

The sensitivity of the hydrate saturation to the aqueous phase methane concentration under Lw-V equilibrium at postdissociation $P / T$ conditions was omitted from the sensitivity analysis in accordance with the arguments presented on the determination of the corresponding aqueous phase volume $V_{W f}$.

(7) Vapour phase methane concentration under (Lw-V) equilibrium, $M_{G f}$ follows. Determination of vapour phase methane concentration under $\mathrm{Lw}-\mathrm{V}$ equilibrium requires determination of both (1) vapour phase mole fraction of methane, $y_{\mathrm{CH}_{4}}$, and (2) molar volume of vapour in equilibrium with the aqueous phase, $M V_{V\left(\mathrm{CH}_{4}+\mathrm{H}_{2} \mathrm{O}\right) @(\mathrm{Lw}-\mathrm{V})}$. The mole fraction of methane in vapour can be determined by using the model developed by Duan and Mao [79]. The method requires inputs form Shibue [89] and Wagner and Pruss [90]. Alternatively, the semiempirical method of Mohammadi et al. [91] can also be used to determine the mole fraction of methane in vapour. The aqueous phase methane concentration which is required as an input in the previous calculation 
procedures is considered negligible. Greater accuracy can be obtained by using the model of Chapoy et al. [88] to determine aqueous phase methane mole fractions over the temperature range of $275-313 \mathrm{~K}$ and pressures up to $18 \mathrm{MPa}$. According to Duan and Mao [79] the model results of Chapoy et al. [88] closely represents experimental measurements over the aforementioned $P / T$ range. The molar volume of vapour in equilibrium with the aqueous phase can be determined using the model presented by Sun et al. [92] and the CSMGem calculator. Both the model of Sun et al. [92] and CSMGem could be used to predict the vapour phase composition for the $\mathrm{CH}_{4}-\mathrm{H}_{2} \mathrm{O}$ system too. The CSMGem calculator generates the phase composition and molar volume at given $P / T$ conditions for methane and water in $\mathrm{Lw}-\mathrm{V}$ equilibrium at corresponding feed compositions. If the mole fraction of methane and the molar volume of the vapour are known, the vapour phase methane concentration can be computed as follows:

$$
M_{G f}=\frac{y_{\mathrm{CH}_{4}}}{M V_{V\left(\mathrm{CH}_{4}+\mathrm{H}_{2} \mathrm{O}\right) @(\mathrm{Lw}-\mathrm{V})}} .
$$

Table 2 illustrates the use of the estimates of volumetric properties and methane density in the hydrate saturation calculation at measured $P / T$ conditions immediately prior to testing (within hydrate stability zone) or at final system equilibrium (outside hydrate stability zone) for three different scenarios: (a) complete hydrate formation is achieved in a water-rich environment allowing no free gas to be present immediately prior to testing; (b) complete hydrate formation is achieved in a gas-rich environment allowing no free water to be present immediately prior to testing (c) incomplete hydrate formation in either water-or gas-rich environment leaving all three $\mathrm{H}-\mathrm{Lw}-\mathrm{V}$ phases in the system.

\section{A Sensitivity Analysis for DGEM}

A sense of accuracy for a given measurement or method of estimation involving several measurements and assumptions can only be developed through a proper sensitivity analysis. The sensitivity of the DGEM estimated hydrate saturation was investigated against the measurements during a typical test, estimates of volumetric properties, and assumptions associated with the DGEM method. For the purpose of performing the sensitivity analysis, measurements for a typical test conducted at the GGHRL at the University of Calgary were combined with the hydrate saturation estimation detailed as per section (b) of Table 2 for formation of hydrates in gas-rich environment.

\subsection{Sensitivity of Hydrate Saturation to Direct Temperature} Measurements, Absolute Pre- and Post-Dissociation Pressures, and Estimates of Volumetric Parameters. Table 3 illustrates the sensitivity of the hydrate saturation to number of test parameters. It should be noted that most of the test parameters are "secondary" as they are derived from multiple "primary" laboratory measurements. Preferably, the sensitivity of hydrate saturation is evaluated against the secondary parameters but not against the primary measured parameters. The objective is to allow the use of more than one method in deriving the secondary parameters at the laboratory. As such the sensitivities presented herein would be more meaningful and useful to the reader.

The sensitivities presented in Table 3 are based on functional tables developed by calculating the hydrate saturation at different values of a test parameter within the mentioned range of validity. The functional tables were converted into graphical form, and empirical equations were developed by fitting linear trend-lines. Therefore it should be noted that although we have retained nine-digit accuracy for the sensitivity derived from the constants of an empirical equation, the equation itself is by no means this accurate. The accuracy of the sensitivity calculation is therefore limited by the uncertainty in the estimation of hydrate saturation which is attributed to the uncertainties of various mathematical models used and the assumptions made during the process of estimation. However, this does not underestimate the usefulness of sensitivity values presented in Table 3 (given a calculation procedure) as it is very important in any experiment to know the "uncertainty" or the "estimated amount by which the observed or calculated value of a quantity may differ from the true value" [93] due to errors in measurement. Errors in measurement could either be systematic (occurring due to errors in calibration or inappropriate use of a measuring instrument) or random (occurring due to uncontrolled variables such as minor fluctuations in environmental conditions or due to specimen variations).

Provided that appropriate measuring instruments under existing environmental conditions are used during the test, the total uncertainty in the measurement (test parameter) can be calculated considering the "accuracy" and the "precision" of the instruments. The "accuracy" of an instrument is related to the instrument calibration and the physical standards against which the instrument is calibrated and is defined as "a certification of how closely" for an instrument to "be expected to agree with its calibration standard" [93]. "The precision of an instrument is the index of its discriminating ability. It is usually stated as the instrument's smallest scale division" [93]. It should also be noted that certain test parameters depend on more than one measured quantity (e.g., initial volume of soil voids). In such situations, the error analysis should consist of error propagation calculations as well. Once the total uncertainty of the measurement is calculated, the sensitivity values presented can be used to calculate the corresponding uncertainty that should be expected in the estimated hydrate saturation.

4.2. Sensitivity to Estimates of Methane Density. Based on our previous presentation of available resources for methane density estimations, the following models were chosen to generate methane density estimates for hydrates formed in gas-rich environment: EoS of Duan et al. [71], CSMGem calculator of Colorado School of Mines [57], Duan and Mao [79] model, and the Ideal Gas Law. The Ideal Gas Law is used here only as a method associated with minimal computational effort. The hydrate saturations obtained with the use of Ideal Gas Law can then be compared with those obtained by employing the other models to generate a feel for the value of extra effort associated with those other models. 


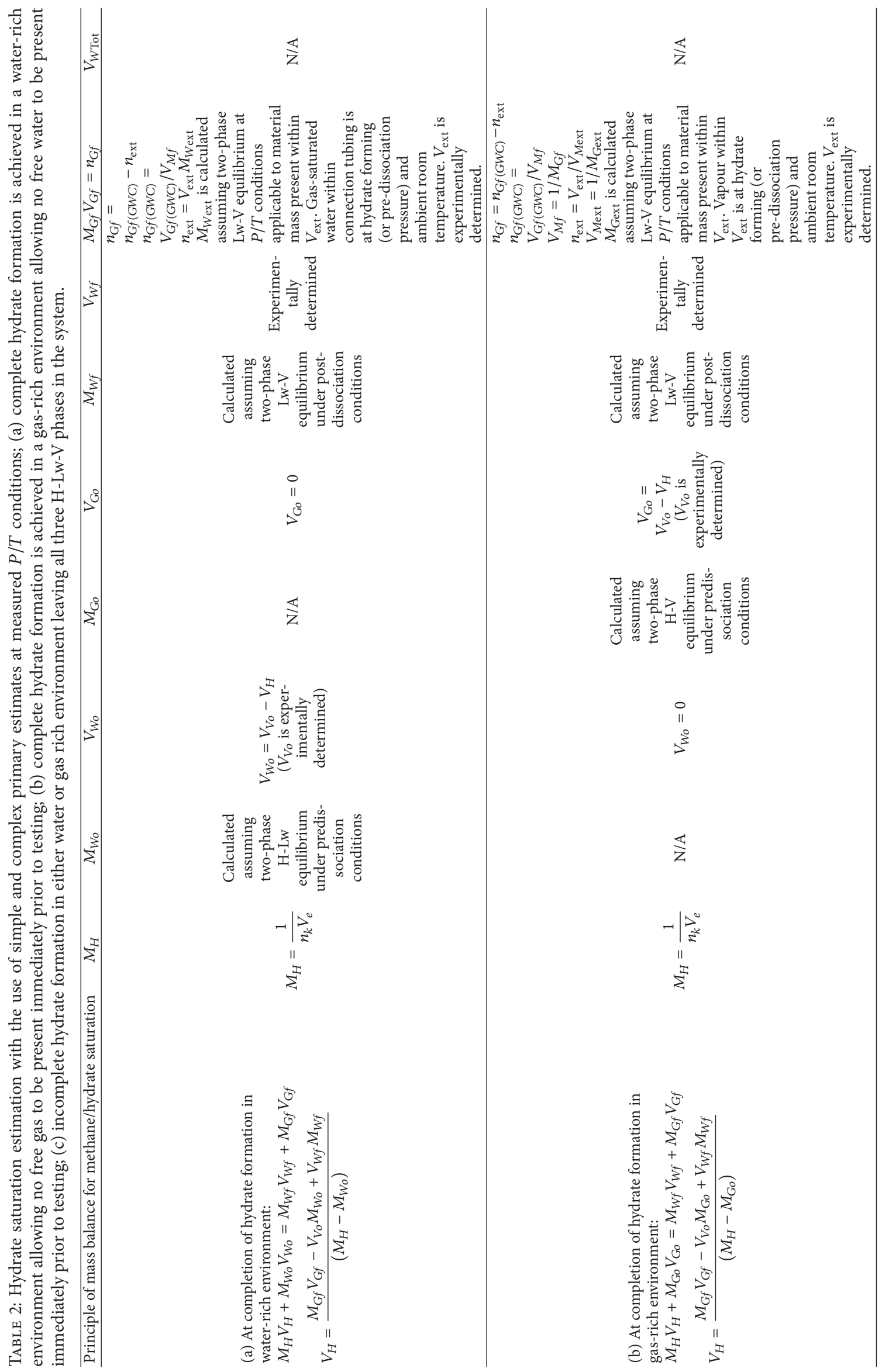




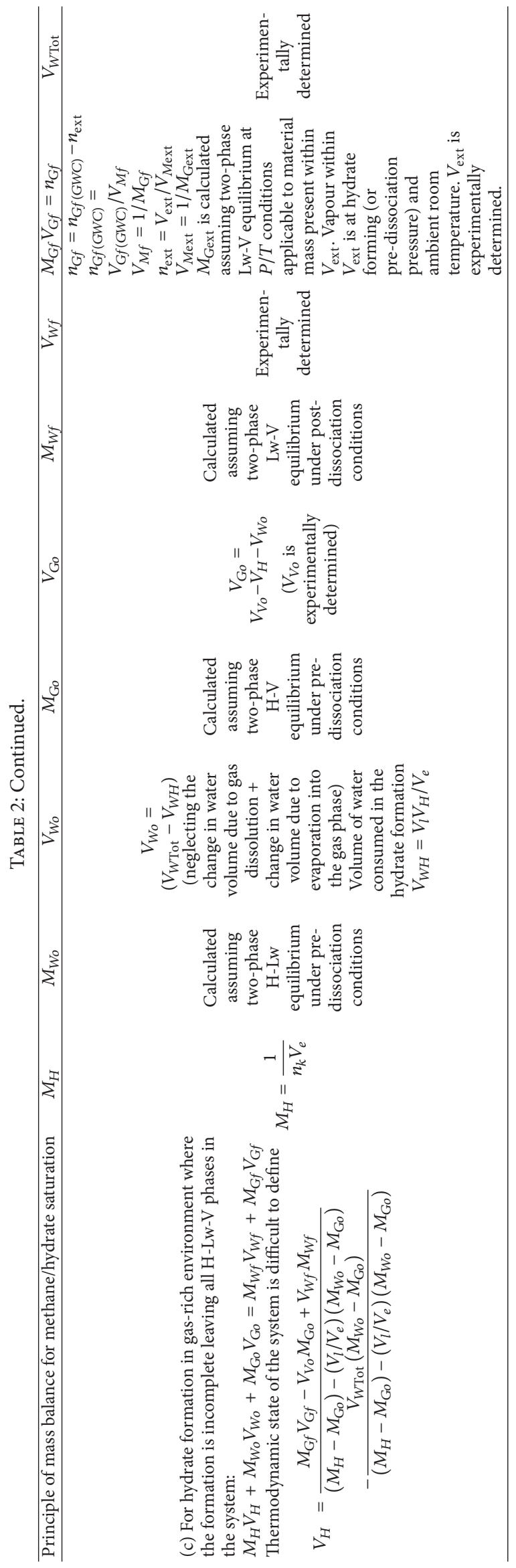


TABLE 3: Sensitivity of hydrate saturation to direct temperature measurements, absolute pre- and post-dissociation system pressures, and estimates of volumetric parameter: the absolute pressures are obtained by combination of gauge and ambient pressures. The volume of gas collected at the gas/water collector $V_{G f(G W C)}$ is obtained with the use of measured height and diameter of the gas column. The volume of hydrate forming gas-filled elements external to the specimen for which the material mass within is forced into the gas/water collector during collection of dissociation products $V_{\text {ext }}$ is predetermined using mass of water occupying the corresponding volume at full water saturation, density of water, ambient temperature, and pressure. The pore volume of the hydrated host sediment $V_{V o}$ is obtained with the use of specimen dimensions (including height and the diameter), grain density, and mass of dry soil.

\begin{tabular}{|c|c|c|c|}
\hline Test parameter & $\begin{array}{l}\text { Sensitivity in terms } \\
\text { of the change in } \\
\text { hydrate saturation }\end{array}$ & Units & Range of validity ${ }^{\mathrm{a}}$ \\
\hline Pre-dissociation temperature $(\mathrm{K})$ within the hydrated specimen & 0.73480982 & $\mathrm{~K}^{-1}$ & $274.15-283.15 \mathrm{~K}$ \\
\hline Postdissociation temperature at the gas/water collector $(\mathrm{K})$ & 0.92676320 & $\mathrm{~K}^{-1}$ & $290.15-297.15 \mathrm{~K}$ \\
\hline Ambient room temperature $(\mathrm{K})$ & 0.15316374 & $\mathrm{~K}^{-1}$ & $293.15-303.15 \mathrm{~K}$ \\
\hline Pre-dissociation pressure (absolute) $(\mathrm{kPa})$ & 0.01702934 & $\mathrm{kPa}^{-1}$ & $9026.325-9276.325 \mathrm{kPa}$ \\
\hline Postdissociation pressure (absolute) at the gas/water collector $(\mathrm{kPa})$ & 0.59329482 & $\mathrm{kPa}^{-1}$ & $400-470 \mathrm{kPa}$ \\
\hline Volume of gas collected at the gas/water collector, $V_{G f(G W C)}(\mathrm{cc})$ & 0.04929067 & $\left(\mathrm{~cm}^{3}\right)^{-1}$ & $5295-5357.5 \mathrm{cc}$ \\
\hline $\begin{array}{l}\text { Volume of hydrate forming gas-filled elements external to the specimen } \\
\text { for which the material mass within is forced into the gas/water collector } \\
\text { during collection of dissociation products, } V_{\text {ext }}(\mathrm{cc})\end{array}$ & 1.14748275 & $\left(\mathrm{~cm}^{3}\right)^{-1}$ & $21-26 c c$ \\
\hline $\begin{array}{l}\text { Pore volume of the hydrated host sediment immediately prior to testing, } \\
V_{V o}(\mathrm{cc})\end{array}$ & 1.60985040 & $\left(\mathrm{~cm}^{3}\right)^{-1}$ & $143-148 c c$ \\
\hline
\end{tabular}

${ }^{a}$ Within the range of validity, hydrate saturation calculated as per section (b) of Table 2 exhibits a linear relationship with the test parameter.

4.2.1. Methane Density of the Hydrate Phase-Hydrate Number $n_{k}$. The sensitivity of the hydrate saturation to the hydrate number was investigated by computing the hydrate saturation for a typical test over a range of hydrate numbers from 5.75 to 6.00 at formation conditions given by a temperature of $278.15 \mathrm{~K}$ and pressure of $9101.325 \mathrm{kPa}$. The resulting functional table was then used to develop an empirical correlation by fitting a linear trend-line. A sensitivity of 0.01234504 change in hydrate saturation per percentage change in hydrate number was derived. The range of hydrate numbers over which the sensitivity was evaluated to extend beyond the range of experimentally determined hydrate numbers at the stated $P / T$ conditions. However, with very little amount of experimental data and our modest understanding of the factors governing the hydrate cage occupancy uncertainties still exist as to the adequacy of the range of hydrate numbers selected for the analysis. However, compared to the sensitivities of hydrate saturation to other parameters subjected to investigation, the derived sensitivity to hydrate number appears less significant.

4.2.2. Methane Density of Vapour Phase under the (H-V) Equilibrium at Predissociation Conditions $M_{G o}$. The application of DGEM in hydrate saturation estimation for hydrates formed in gas-rich environment assumes $\mathrm{H}-\mathrm{V}$ equilibrium under pre-dissociation conditions. The hydrate saturation at the previous assumption of two-phase $\mathrm{H}-\mathrm{V}$ equilibrium conditions was evaluated by determining hydrate saturation with the use of CSMGem calculator [57], the EoS developed by Duan et al. [71], and the Ideal Gas Law. The use of Duan model and Ideal Gas Law neglects the presence of moisture in vapour. Apparently, CSMGem calculator too seems to be neglecting the presence of moisture, and, hence, the vapour is approximated to a single component pure $\mathrm{CH}_{4}$ system.
If CSMGem is assumed to accommodate the presence of moisture in gas phase, the mere comparison of the hydrate saturation values obtained by CSMGem [57] and Duan et al. [71] may suggest that the sensitivity to the assumption of moisture free gas phase appears to have little effect over the hydrate saturation. However, the difference between the CSMGem [57] and Duan et al. [71] based predictions cannot be completely attributed to the consideration of presence or absence of moisture in the gas phase, as there could be other differences between the two calculation procedures contributing to the difference in predicted saturations. As such the available resources do not allow us to investigate the effects of possible existence of nonequilibrium conditions within the system or the treatment of water-hydrocarbon interaction. The hydrate saturations obtained are presented in Table 4 . The calculations were performed at pre-dissociation temperature of $278.15 \mathrm{~K}$ and pressure of $9101.325 \mathrm{kPa}$. It is also interesting to note that the results generated with the use of Ideal Gas Law deviate greatly from the rest and highlight the usefulness of other methods at high pressures and low temperatures as the real gases stray from ideal conditions.

4.2.3. Methane Density of Vapour Phase under ( $L w$-V) Equilibrium at Postdissociation Conditions at the Gas/Water Collector $M_{G f}$. The application of DGEM assumes Lw-V two phase equilibrium under the post-dissociation conditions. As such we investigate the sensitivity of the hydrate saturation to existence of nonequilibrium conditions in the gaseous phase. If the vapour phase water content in methane is neglected assuming gaseous phase of pure $\mathrm{CH}_{4}$ within the gas/water collector, the molar volume of methane under the postdissociation conditions can be calculated using the Ideal Gas Law or the EoS of Duan et al. [71]. The approaches such as the model developed by Duan and Mao [79] and CSMGem [57] 
TABLE 4: Sensitivity of hydrate saturation to the choice of vapour phase EoS at $\mathrm{H}-\mathrm{V}$ equilibrium under the pre-dissociation conditions.

\begin{tabular}{lcc}
\hline Description & $\begin{array}{c}\text { Molar volume of } \\
\text { methane } \\
\left(\mathrm{cm}^{3} / \mathrm{mol}\right)\end{array}$ & $\begin{array}{c}\text { Hydrate } \\
\text { saturation (\%) }\end{array}$ \\
\hline CSMGem & 210.13 & 47.74 \\
EoS of Duan et al. [71] & 206.8594 & 46.20 \\
Ideal Gas Law & 254.1026 & 60.20 \\
\hline
\end{tabular}

accommodate the effect due to the presence of moisture in the vapour phase. The CSMGem calculator [57] is calibrated for water-hydrocarbon systems by regressing water-hydrocarbon interaction parameters available in GPA Thermodynamic Database [94]. The hydrate saturations obtained with the use of aforementioned at post-dissociation temperature of $296.15 \mathrm{~K}$ and pressure of $445.325 \mathrm{kPa}$ are presented in Table 5. The results show a moderate sensitivity to the treatment of water-hydrocarbon interaction in the gaseous phase. At the test $P / T$ conditions, there exists a difference of only 1.62 in percentage hydrate saturation between the two Duan models. Interestingly, the hydrate saturation generated by the Ideal Gas Law appears to be in good agreement with those other methods. Therefore, it is suggested that under conditions of high temperature and low pressure, a model such as Ideal Gas Law which is associated with the least computation effort can be employed in the saturation calculation without significant loss of accuracy.

4.2.4. Methane Density of Vapour Phase under the (Lw-V) Equilibrium for the Material Mass Present within Total Volume of Hydrate Forming Gas-Filled Elements External to the Immediate Boundaries of the Specimen $M_{\text {Gext }}$. When hydrate dissociation products are collected and post-dissociation gas PVT measurements are performed at separate gas/water collector external to the hydrated specimen, a quantity of gas external to the specimen and present within such elements as connection tubing between the specimen and the collector may enter into the collector resulting in an overestimation of the moles of methane generated from hydrate dissociation. Therefore, this quantity of gas should be estimated and detached from the hydrate saturation calculation. Under the prevailing conditions at GGHRL at the University of Calgary, such connection tubing consists of vapour saturated gaseous methane at formation pressure and room temperature. A similar procedure to the previously mentioned (for vapour phase methane density under Lw$\mathrm{V}$ equilibrium at the gas/water collector) was followed to check the sensitivity to the assumption of Lw-V two phase equilibrium in the determination of the quantity of gas within respective external volume under corresponding $P / T$ conditions. The results are shown in Table 6 for a typical test at a (room) temperature of $299.15 \mathrm{~K}$ and a pressure of $9101.325 \mathrm{kPa}$. Similar to the previous case, of estimating $M_{G f}$, the fact that whether or not the gaseous phase is saturated with water does not appear to have significant impact over the estimated hydrate saturation. However, as opposed to the
TABLE 5: Sensitivity to the choice of vapour phase EoS at $\mathrm{Lw}-\mathrm{V}$ equilibrium under post-dissociation conditions.

\begin{tabular}{lcc}
\hline Description & $\begin{array}{c}\text { Molar volume of } \\
\text { methane } \\
\left(\mathrm{cm}^{3} / \mathrm{mol}\right)\end{array}$ & $\begin{array}{c}\text { Hydrate } \\
\text { saturation (\%) }\end{array}$ \\
\hline $\begin{array}{l}\text { Vapour saturated gas phase } \\
\text { using Duan and Mao, 2006 }\end{array}$ & 5520.98 & 44.58 \\
[79] & & \\
EoS of Duan et al. [71] & 5486.85 & 46.20 \\
CSMGem & 5523.34 & 44.47 \\
Ideal Gas Law & 5529.29 & 44.19 \\
\hline
\end{tabular}

TABLE 6: Sensitivity to the choice of vapour phase EoS at Lw$\mathrm{V}$ equilibrium for quantity of gas present within such elements external to the immediate boundaries of the specimen for which the material present within is forced into the gas/water collector during collection of dissociation products.

\begin{tabular}{lcc}
\hline Description & $\begin{array}{c}\text { Molar volume of } \\
\text { methane } \\
\left(\mathrm{cm}^{3} / \mathrm{mol}\right)\end{array}$ & $\begin{array}{c}\text { Hydrate } \\
\text { saturation (\%) }\end{array}$ \\
\hline $\begin{array}{l}\text { Vapour saturated gas phase } \\
\text { using Duan and Mao, 2006 }\end{array}$ & 236.03 & 46.24 \\
[79] & & \\
EoS of Duan et al. [71] & 235.69 & 46.20 \\
CSMGem & 239.33 & 46.61 \\
Ideal Gas Law & 273.29 & 49.90 \\
\hline
\end{tabular}

hydrate saturations obtained for vapour phase under postdissociation conditions at the gas/water collector, the use of Ideal Gas Law results in significant overestimation of hydrate saturation. This is due to the fact that real gases deviate from ideal conditions at high pressures. The results indicate the necessity for approximating the actual test conditions with appropriate models of adequate accuracy.

\section{Conclusions}

The use of DGEM method for estimation of hydrate saturation proves to be a useful methodology as the estimated quantities are independent of intact sediment characteristics, pore space consistency, hydrate growth habit, and hydrate distribution. The calculation is based on the principle of mass balance for methane and volume compatibility of the phases present within the system. However, the task is not less challenging as the accuracy of the estimation greatly depends on (1) the degree of care we exert in performing numerous measurements at the laboratory and (2) how well the hydrated soil system is modelled with physical and chemical equilibrium conditions that are assumed. Therefore, we perform a sensitivity analysis highlighting the need for minimizing measurement errors and evaluating the consequences of assumed equilibrium conditions not being representative of the true nature of the system. The key findings of the sensitivity analysis on various laboratory measurements can be summarized as follows. 
(i) $P / T$ measurements of the system components at the laboratory are critical, particularly when large quantities of methane are present at low density (specifically at high temperatures and low pressures).

(ii) Volume measurements in the system components are critical when the methane density is at its greatest (high pressure and low temperature).

Laboratory experiments should therefore pay attention to the aforementioned in the selection of measuring devices and apparatus in order to maintain appropriate levels of accuracy in testing.

Under the assumed equilibrium pre-and post dissociation conditions, estimation of methane density in hydrate, aqueous liquid, and vapour phases requires the use of various theoretical models. In fact, lack of or limited access to properly validated theoretical models hinders accurate estimation of hydrate saturation. As such we focus on developing a resource information base for hydrate saturation estimates illustrating the current state of knowledge in related hydrate sciences. In this effort, we have attempted suggesting the use of those models that are validated against experimental data in many situations as possible. The key findings of the sensitivity analysis for hydrates formed in gas-rich environment on the assumed equilibrium conditions of the system under which methane density of different phases are estimated suggest that neglecting the water content in vapour phase, as done with the use of single component models, does not appear to result in significant change in the estimated hydrate saturations. It, therefore, appears that the consequences of assumed equilibrium conditions not being representative of the true nature of the system have no significant impact on the estimated hydrate saturations. As a result, the DGEM method for hydrate saturation estimation yields results representative of the true hydrate saturation present within a given sediment, provided that adequate care is exerted at the laboratory to minimize measurement errors. Additionally, the analysis presented in Section 4.2 extends to investigate when and where it is appropriate to use models such as Ideal Gas Law which is associated with minimal computational effort and cautions against the use of the Ideal Gas Law for approximation of moist gaseous methane when conditions stray from ideal conditions.

\section{Notations}

$$
\begin{aligned}
& \text { a: } \quad \text { Lattice parameter }(\stackrel{\circ}{A}) \\
& a_{0} \text { : } \quad \text { Lattice parameter }(\stackrel{\circ}{A}) \text { at a reference } \\
& \text { temperature, } T_{o}(\mathrm{~K}) \\
& a_{1}, a_{2}, a_{3} \text { : Lattice constants } \\
& M_{G o} \text { : } \quad \text { Moles of methane present per unit volume } \\
& \text { in vapour phase under predissociation } \\
& \text { conditions }\left(\mathrm{mol} / \mathrm{cm}^{3}\right) \\
& M_{G f} \text { : } \quad \text { Moles of methane present per unit volume } \\
& \text { of vapour phase under postdissociation } \\
& \text { conditions }\left(\mathrm{mol} / \mathrm{cm}^{3}\right)
\end{aligned}
$$

$M_{\text {Gext }}$ : Moles of methane present per unit volume of vapour phase volume $V_{\text {ext }}$ under $\mathrm{L}-\mathrm{V}$ equilib$\operatorname{rium}\left(\mathrm{mol} / \mathrm{cm}^{3}\right)$

$M_{H}$ : $\quad$ Moles of methane present per unit volume in hydrate phase $\left(\mathrm{mol} / \mathrm{cm}^{3}\right)$

$M_{W o}$ : Moles of methane present per unit volume of aqueous liquid under pre-dissociation conditions $\left(\mathrm{mol} / \mathrm{cm}^{3}\right)$

$M_{W f}$ : Moles of methane present per unit volume of aqueous liquid under post-dissociation conditions $\left(\mathrm{mol} / \mathrm{cm}^{3}\right)$

$M_{\text {Wext }}$ : Moles of methane present per unit volume of liquid phase volume $V_{\text {ext }}$ under $\mathrm{Lw}-\mathrm{V}$ equilibrium $\left(\mathrm{mol} / \mathrm{cm}^{3}\right)$

$M V_{L w}: \quad$ Molar volume of aqueous liquid $\left(\mathrm{cm}^{3} / \mathrm{mol}\right)$

$M V_{V}: \quad$ Molar volume of vapour $\left(\mathrm{cm}^{3} / \mathrm{mol}\right)$

$n_{\text {ext }}$ : Total number of gas moles present within the volume $V_{\text {ext }}(\mathrm{mol})$

$n_{G f}$ : The total number of gas moles present within the gas/water collector $\left(n_{G f(G W C)}\right)$ less the total number of gas moles present within the connection tubing $\left(n_{\text {ext }}\right)(\mathrm{mol})$

$n_{G f(G W C)}$ : Total number of gas moles present within the gas/water collector at post-dissociation conditions (mol)

$n_{k}: \quad$ Hydrate number

$P: \quad$ Pressure $(\mathrm{kPa})$

$V: \quad$ Volume $\left(\mathrm{cm}^{3}\right)$

$V_{\text {ext }}: \quad$ Volume of hydrate forming gas-filled elements external to the immediate boundaries of the specimen for which the material mass within is forced into the gas/water collector during collection of dissociation products $\left(\mathrm{cm}^{3}\right)$

$V_{d}: \quad$ Volume change in the gas phase due to gas dissolution in the liquid phase under pre-dissociation conditions $\left(\mathrm{cm}^{3}\right)$

$V_{d}^{\prime}: \quad$ Volume change in the liquid phase due to gas dissolution in the liquid phase under pre-dissociation conditions $\left(\mathrm{cm}^{3}\right)$

$V_{e}: \quad$ Volume of hydrate lattice per mole of water at pre-dissociation conditions $\left(\mathrm{cm}^{3} / \mathrm{mol}\right)$

$V_{G o}$ : Volume of water saturated gaseous methane (vapour) present within the system under predissociation conditions $\left(\mathrm{cm}^{3}\right)$

$V_{G f}$ : Volume of water saturated gaseous methane (vapour) corresponding to the number of gas moles $n_{G f}$ under post-dissociation conditions $\left(\mathrm{cm}^{3}\right)$

$V_{G f(G W C)}$ : Total volume of gas collected at the gas/water collector under Lw-V equilibrium at post-dissociation conditions $\left(\mathrm{cm}^{3}\right)$

$V_{G H}$ : Volume of gas consumed for hydrate formation $\left(\mathrm{cm}^{3}\right)$

$V_{\text {GTot }}$ : Total volume of gas available for hydrate formation under pre-dissociation conditions $\left(\mathrm{cm}^{3}\right)$

$V_{H}$ : Volume of hydrates under pre-dissociation conditions $\left(\mathrm{cm}^{3}\right)$

$V_{l}$ : $\quad$ Partial molar volume of water in the solution at pre-or post-dissociation conditions $\left(\mathrm{cm}^{3} / \mathrm{mol}\right)$ 
$V_{M e x t}:$ Molar volume of methane under Lw-V equilibrium at $P / T$ conditions (i.e., pre-dissociation pressure and room temperature) corresponding to the vapour volume $V_{\text {ext }}\left(\mathrm{cm}^{3} / \mathrm{mol}\right)$

$V_{M f}:$ Molar volume of methane under Lw-V equilibrium at post-dissociation conditions $\left(\mathrm{cm}^{3} / \mathrm{mol}\right)$

$V_{S}$ : Volume of solid soil (constant under pre- and post-dissociation conditions) $\left(\mathrm{cm}^{3}\right)$

$V_{W o}$ : Volume of (gas dissolved) water present within the system under pre-dissociation conditions $\left(\mathrm{cm}^{3}\right)$

$V_{W f}$ : Volume of (gas dissolved) water present within the system under post-dissociation conditions $\left(\mathrm{cm}^{3}\right)$

$V_{W H}$ : Volume of water generated due to hydrate dissociation or consumed in hydrate formation $\left(\mathrm{cm}^{3}\right)$

$V_{W \text { Tot }}$ : Total volume of water available for hydrate formation under pre-dissociation conditions $\left(\mathrm{cm}^{3}\right)$

$V_{W V}$ : Volume change in the gas phase due to the presence of moisture $\left(\mathrm{cm}^{3}\right)$

$V_{W V}^{\prime}$ : Volume change in the aqueous liquid due to the moisture loss into the gas phase $\left(\mathrm{cm}^{3}\right)$

$V_{V o}$ : Initial volume of voids under pre-dissociation conditions $\left(\mathrm{cm}^{3}\right)$

T: $\quad$ Temperature (K)

$x_{\mathrm{CH}_{4}}$ : Mole fraction of methane in aqueous liquid

$y_{\mathrm{CH}_{4}}$ : Mole fraction of methane in vapour phase.

\section{Acknowledgments}

The authors wish to gratefully acknowledge three anonymous reviewers for their helpful comments in reviewing this paper. The authors also wish to gratefully acknowledge the financial contributions from Natural Sciences and Engineering Research Council (NSERC) of Canada.

\section{References}

[1] I. F. Makogon, Hydrates of Natural Gas, PennWell Books, Tulsa, Okla, USA, 1981.

[2] T. Ebinuma, Y. Kamata, H. Minagawa, R. Ohmura, J. Nagao, and H. Narita, "Mechanical properties of sandy sediment containing methane hydrate," in Proceedings of the 5th International Conference on Gas Hydrates, pp. 958-961, Tapir Academic Pressemic Press, Trondheim, Norway, 2005.

[3] M. Hyodo, Y. Nakata, N. Yoshimoto, and R. Orense, "Shear behaviour of methane hydrate-bearing sand," in Proceedings of the 17th International Offshore and Polar Engineering Conference, (ISOPE '07), pp. 1326-1333, Lisbon, Portugal, July 2007.

[4] M. Hyodo, Y. Nakata, N. Yoshimoto, R. Orense, and J. Yoneda, "Bonding strength by methane hydrate formed among sand particles," in Proceedings of the 6th International Conference on Micromechanics of Granular Media, Powders and Grains, pp. 7982, Golden, Colo, USA, July 2009.

[5] M. Hyodo, J. Yoneda, Y. Nakata, and N. Yoshimoto, "Strength and dissociation property of methane hydrate bearing sand," in Proceedings of the 7th International Conference on Gas Hydrates (ICGH '11), Edinburgh, UK, 2011.

[6] K. Miyazaki, A. Masui, K. Aoki, Y. Sakamoto, T. Yamaguchi, and S. Okubo, "Strain-rate dependence of triaxial compressive strength of artificial methane-hydrate-bearing sediment," International Journal of Offshore and Polar Engineering, vol. 20, no. 4, pp. 256-264, 2010.

[7] K. Miyazaki, A. Masui, H. Haneda, Y. Ogata, K. Aoki, and T. Yamaguchi, "Variable-compliance-type constitutive model for methane hydrate bearing sediment," in Proceedings of the 6th International Conference on Gas Hydrates, Vancouver, Canada, 2008.

[8] K. Miyazaki, A. Masui, Y. Sakamoto, N. Tenma, and T. Yamaguchi, "Effect of confining pressure on triaxial compressive properties of artificial methane hydrate bearing sediments," in Proceedings of the Offshore Technology Conference (OTC '10), pp. 1823-1831, Houston, Tex, USA, May 2010.

[9] K. Miyazaki, A. Masui, Y. Sakamoto, K. Aoki, N. Tenma, and T. Yamaguchi, "Triaxial compressive properties of artificial methane-hydrate-bearing sediment," Journal of Geophysical Research, vol. 116, no. B6, Article ID B06102, 2011.

[10] A. Masui, H. Haneda, Y. Ogata, and K. Aoki, "The effect of saturation degree of methane hydrate on the shear strength of synthetic methane hydrate sediments," in Proceedings of the International Conference on Gas Hydrates, pp. 364-369, Tapir Academic Press, Trondheim, Norway, June 2005.

[11] A. Masui, K. Miyazaki, H. Haneda, Y. Ogata, and K. Aoki, "Mechanical properties of natural gas hydrate bearing sediments retrieved from eastern Nankai trough," in Proceedings of the Offshore Technology Conference (OTC '08), Houston, Tex, USA, 2008.

[12] A. Masui, K. Miyazaki, H. Haneda, Y. Ogata, and K. Aoki, "Mechanical characteristics of natural and artificial gas hydrate bearing sediments," in Proceedings of the 6th International Conference on Gas Hydrates, Chevron, Vancouver, Canada, 2008.

[13] H. Ghiassian and J. L. H. Grozic, "Undrained triaxial testing of methane hydrate bearing soil specimens," in Proceedings of the 7th International Conference on Gas Hydrates, Edinburgh, UK, 2011.

[14] W. J. Winters, W. F. Waite, D. H. Mason, W. P. Dillon, and I. A. Pecher, "Sediment properties associated with gas hydrate formation," in Proceedings of the 4rth International Conference on Gas Hydrates, Japan National Oil Corporation, Yokohama, Japan, 2002.

[15] W. J. Winters, W. F. Waite, D. H. Mason, L. Y. Gilbert, and I. A. Pecher, "Methane gas hydrate effect on sediment acoustic and strength properties," Journal of Petroleum Science and Engineering, vol. 56, no. 1-3, pp. 127-135, 2007.

[16] T. S. Yun, C. J. Santamarina, and C. Ruppel, "Mechanical properties of sand, silt, and clay containing tetrahydrofuran hydrate," Journal of Geophysical Research B, vol. 112, no. 4, Article ID B04106, 2007.

[17] V. R. Parameswaran, M. Paradis, and Y. P. Handa, "Strength of frozen sand containing tetrahydrofuran hydrate," Canadian Geotechnical Journal, vol. 26, no. 3, pp. 479-483, 1989.

[18] I. Cameron, Y. P. Handa, and T. H. W. Baker, "Compressive strength and creep behavior of hydrate-consolidated sand," Canadian Geotechnical Journal, vol. 27, no. 2, pp. 255-258, 1990.

[19] W. F. Waite, J. C. Santamarina, D. D. Cortes et al., "Physical properties of hydrate-bearing sediments," Reviews of Geophysics, vol. 47, Article ID RG4003, 2009.

[20] T. J. Kneafsey, Y. Seol, A. Gupta, and L. Tomutsa, "Permeability of laboratory-formed methane-hydrate-bearing sand: measurements and observations using X-ray computed tomography," SPE Journal, vol. 16, no. 1, pp. 78-94, 2011. 
[21] H. Minagawa, R. Ohmura, Y. Kamata et al., "Water permeability of porous media containing methane hydrate as controlled by the methane-hydrate growth process," in Natural Gas HydratesEnergy Resource Potential and Associated Geologic Hazards, T. Collett, A. Johnson, C. Knapp, and R. Boswell, Eds., pp. 734739, AAPG Memoir 89, Tulsa, Okla, USA, 2009.

[22] A. Kumar, B. Maini, P. R. Bishnoi, M. Clarke, O. Zatsepina, and S. Srinivasan, "Experimental determination of permeability in the presence of hydrates and its effect on the dissociation characteristics of gas hydrates in porous media," Journal of Petroleum Science and Engineering, vol. 70, no. 1-2, pp. 114-122, 2010.

[23] H. Liang, Y. Song, Y. Chen, and Y. Liu, "The measurement of permeability of porous media with methane hydrate," Petroleum Science and Technology, vol. 29, no. 1, pp. 79-87, 2011.

[24] C. Ordonez, J. L. H. Grozic, and J. Chen, "Hydraulic conductivity of Ottawa sand specimens containing R-11 gas hydrates," in Proceedings of the 62nd Canadian Geotechnical Conference, Halifax, Canada, 2009.

[25] S. Chand, T. A. Minshull, J. A. Priest, A. I. Best, C. R. I. Clayton, and W. F. Waite, "An effective medium inversion algorithm for gas hydrate quantification and its application to laboratory and borehole measurements of gas hydrate-bearing sediments," Geophysical Journal International, vol. 166, no. 2, pp. 543-552, 2006.

[26] J. J. Howard, K. C. Hester, J. C. Stevens, and M. B. Rydzy, "Ultrasonic velocity measurements during experimental $\mathrm{CH}_{4}$ hydrate formation and $\mathrm{CO}_{2}$ exchange," in Proceedings of the 7th International Conference on Gas Hydrates (ICGH '11), Edinburgh, UK, 2011.

[27] R. L. Kleinberg, C. Flaum, D. D. Griffin et al., "Deep sea NMR: methane hydrate growth habit in porous and its relationship to hydraulic permeability, deposit accumulation, and submarine slope stability," Journal of Geophysical Research B, vol. 108, no. 10, pp. 1-17, 2003.

[28] J. A. Priest, A. I. Best, and C. R. I. Clayton, "A laboratory investigation into the seismic velocities of methane gas hydratebearing sand," Journal of Geophysical Research B, vol. 110, no. 4, pp. 1-13, 2005.

[29] J. A. Priest, E. V. L. Rees, and C. R. I. Clayton, "Influence of gas hydrate morphology on the seismic velocities of sands," Journal of Geophysical Research, vol. 114, Article ID B11205, 2009.

[30] W. F. Waite, T. J. Kneafsey, W. J. Winters, and D. H. Mason, "Physical property changes in hydrate-bearing sediment due to depressurization and subsequent repressurization," Journal of Geophysical Research B, vol. 113, no. 7, Article ID B07102, 2008.

[31] W. J. Winters, I. A. Pecher, W. F. Waite, and D. H. Mason, "Physical properties and rock physics models of sediment containing natural and laboratory-formed methane gas hydrate," American Mineralogist, vol. 89, no. 8-9, pp. 1221-1227, 2004.

[32] J. R. Kliner and J. L. H. Grozic, "Determination of synthetic hydrate content in sand specimens using dielectrics," Canadian Geotechnical Journal, vol. 43, no. 6, pp. 551-562, 2006.

[33] E. Spangenberg and J. Kulenkampff, "Influence of methane hydrate content on electrical sediment properties," Geophysical Research Letters, vol. 33, no. 24, Article ID L24315, 2006.

[34] W. F. Waite, B. J. de Martin, S. H. Kirby, J. Pinkston, and C. D. Ruppel, "Thermal conductivity measurements in porous mixtures of methane hydrate and quartz sand," Geophysical Research Letters, vol. 29, no. 24, Article ID 015988, pp. 82-1-82-4, 2002.

[35] W. F. Waite, L. A. Stern, S. H. Kirby, W. J. Winters, and D. H. Mason, "Simultaneous determination of thermal conductivity, thermal diffusivity and specific heat in sI methane hydrate," Geophysical Journal International, vol. 169, pp. 767-774, 2007.

[36] D. R. Murray, R. L. Kleinberg, B. K. Sinha et al., "Saturation, acoustic properties, growth habit, and state of stress of a gas hydrate reservoir from well logs," Petrophysics, vol. 47, no. 2, pp. 129-137, 2006.

[37] M. B. Helgerud, Wave speeds in gas hydrate and sediments containing gas hydrate: a laboratory and modeling study [Ph.D. thesis], Stanford University, Stanford, Calif, USA, 2001.

[38] E. Spangenberg, J. Kulenkampff, R. Naumann, and J. Erzinger, "Pore space hydrate formation in a glass bead sample from methane dissolved in water," Geophysical Research Letters, vol. 32, no. 24, 2005.

[39] Y. Seol, E. Myshakin, and T. Kneafsey, "Quantitative applications of X-Ray CT observations for core-scale hydrate studies," in Proceedings of the 7th International Conference on Gas Hydrates, Edinburgh, UK.

[40] M. W. Lee and T. S. Collett, "Gas hydrate saturations estimated from fractured reservoir at Site NGHP-01-10, Krishna-Godavari Basin, India," Journal of Geophysical Research B, vol. 114, no. 7, Article ID B07102, 2009.

[41] Y. P. Handa, "Compositions, enthalpies of dissociation, and heat capacities in the range 85 to $270 \mathrm{~K}$ for clathrate hydrates of methane, ethane, and propane, and enthalpy of dissociation of isobutane hydrate, as determined by a heat-flow calorimeter," The Journal of Chemical Thermodynamics, vol. 18, no. 10, pp. 915-921, 1986.

[42] Y. P. Handa and D. Stupin, "Thermodynamic properties and dissociation characteristics of methane and propane hydrates in 70-Å-radius silica gel pores," Journal of Physical Chemistry, vol. 96, no. 21, pp. 8599-8603, 1992.

[43] A. K. Sum, R. C. Burruss, and E. D. Sloan, "Measurement of clathrate hydrates via Raman spectroscopy," Journal of Physical Chemistry B, vol. 101, no. 38, pp. 7371-7377, 1997.

[44] T. Uchida, T. Hirano, T. Ebinuma et al., "Raman spectroscopic determination of hydration number of methane hydrates," AIChE Journal, vol. 45, no. 12, pp. 2641-2645, 1999.

[45] Y. Seo, H. Lee, and B. J. Ryu, "Hydration number and twophase equilibria of $\mathrm{CH}_{4}$ hydrate in the deep ocean sediments," Geophysical Research Letters, vol. 29, no. 8, pp. 85-4, 2002.

[46] S. Circone, S. H. Kirby, and L. A. Stern, "Direct measurement of methane hydrate composition along the hydrate equilibrium boundary," Journal of Physical Chemistry B, vol. 109, no. 19, pp. 9468-9475, 2005.

[47] T. J. Galloway, W. Ruska, P. S. Chappelear, and R. Kobayashi, "Experimental measurement of hydrate numbers for methane and ethane and comparison with theoretical values," Industrial and Engineering Chemistry Fundamentals, vol. 9, no. 2, pp. 237243, 1970.

[48] D. R. Lide, CRC Handbook of Chemistry and Physics, CRC Press, Boca Raton, Fla, USA, 88th edition, 2007.

[49] K. C. Hester, Z. Huo, A. L. Ballard, C. A. Koh, K. T. Miller, and E. D. Sloan, "Thermal expansivity for sI and sII clathrate hydrates," Journal of Physical Chemistry B, vol. 111, no. 30, pp. 8830-8835, 2007.

[50] A. G. Ogienko, A. V. Kurnosov, A. Y. Manakov et al., "Gas hydrates of argon and methane synthesized at high pressures: composition, thermal expansion, and self-preservation," Journal of Physical Chemistry B, vol. 110, no. 6, pp. 2840-2846, 2006.

[51] V. P. Shpakov, J. S. Tse, C. A. Tulk, B. Kvamme, and V. R. Belosludov, "Elastic moduli calculation and instability in structure I 
methane clathrate hydrate," Chemical Physics Letters, vol. 282, no. 2, pp. 107-114, 1998.

[52] R. Sun and Z. Duan, "An accurate model to predict the thermodynamic stability of methane hydrate and methane solubility in marine environments," Chemical Geology, vol. 244, no. 1-2, pp. 248-262, 2007.

[53] Z. Huo, K. Hester, E. D. Sloan Jr., and K. T. Miller, "Methane hydrate nonstoichiometry and phase diagram," AIChE Journal, vol. 49, no. 5, pp. 1300-1306, 2003.

[54] M. D. Jager, High pressure studies of hydrate phase inhibition using Raman spectroscopy [Ph.D. thesis], Colorado School of Mines, Colo, USA, 2001.

[55] E. D. Sloan, Clathrate Hydrates of Natural Gases, Marcel Decker, New York, NY, USA, 1998.

[56] E. D. Sloan, "Clathrate hydrate measurements: microscopic, mesoscopic, and macroscopic," Journal of Chemical Thermodynamics, vol. 35, no. 1, pp. 41-53, 2003.

[57] A. L. Ballard, A non-ideal hydrate solid solution model for a multi-phase equilibria program [Ph.D. thesis], Chemical and Petroleum-Refining Engineering, Colorado School of Mines, Colo, USA, 2002.

[58] A. Chapoy, C. Coquelet, and D. Richon, "Erratum: revised solubility data and modeling of water in the gas phase of the methane/water binary system at temperatures from 283.08 to $318.12 \mathrm{~K}$ and pressures up to $34.5 \mathrm{MPa}$," Fluid Phase Equilibria, vol. 230, no. 1-2, pp. 210-214, 2005, Fluid Phase Equilibria, vol. 214, pp. 101-117, 2003.

[59] A. Chapoy, H. Haghighi, R. Burgass, and B. Tohidi, "Gas hydrates in low water content gases: experimental measurements and modelling using the CPA equation of state," Fluid Phase Equilibria, vol. 296, no. 1, pp. 9-14, 2010.

[60] G. K. Folas, E. W. Froyna, J. Lovland, G. M. Kontogeorgis, and E. Solbraa, "Data and prediction of water content of high pressure nitrogen, methane and natural gas," Fluid Phase Equilibria, vol. 252, no. 1-2, pp. 162-174, 2007.

[61] T. V. Løkken, A. Bersås, K. O. Christensen, C. F. Nygaard, and E. Solbraa, "Water content of high pressure natural gas: data, prediction and experience from field," in Proceedings of the International Gas Union Research Conference (IGRC '08), pp. 1979-2021, Paris, France, October 2008.

[62] N. E. Kosyakov, B. I. Ivchenko, and P. P. Krishtopa, "Solubility of moisture in compressed argon, methane, and helium at low temperatures," Zhurnal Prikladnoi Khimi, vol. 52, no. 4, pp. 922923, 1979.

[63] L. R. Oellrich and K. Althaus, "GERG-Water Correlation (GERG Technical Monograph TM14) Relationship between water content and water due point keeping in consideration the gas composition in the field of natural gas," Fortschritt-Berichte VDI Reihe 3-Nr. 679, 2000.

[64] Z. Youssef, A. Barreau, P. Mougin, J. Jose, and I. Mokbel, "Measurements of hydrate dissociation temperature of methane, ethane, and $\mathrm{CO}_{2}$ in the absence of any aqueous phase and prediction with the cubic Plus association equation of state," Industrial and Engineering Chemistry Research, vol. 48, no. 8, pp. 4045-4050, 2009.

[65] K. Aoyagi, K. Y. Song, R. Kobayashi, E. D. Sloan, and P. B. Dharmawardhana, "The water content and correlation of the water content of methane in equilibrium with hydrates," Tech. Rep. 45, Gas Processors Association, Tulsa, Okla, USA, 1980.

[66] K. Aoyagi, K. Y. Song, E. D. Sloan, P. B. Dharmawardhana, and R. Kobayashi, "Improved measurements and correlation of the water content of methane gas in equilibrium with hydrate," in Proceedings of the Annual Convention of Gas Processors Association, pp. 25-28, March 1979.

[67] E. D. Sloan, F. M. Khoury, and R. Kobayashi, "Water content of methane gas in equilibrium with hydrates," Industrial and Engineering Chemistry Fundamentals, vol. 15, no. 4, pp. 318-323, 1976.

[68] K. Y. Song, M. Yarrison, and W. Chapman, "Experimental low temperature water content in gaseous methane, liquid ethane, and liquid propane in equilibrium with hydrate at cryogenic conditions," Fluid Phase Equilibria, vol. 224, no. 2, pp. 271-277, 2004.

[69] L. Zhang, R. Burgass, A. Chapoy, and B. Tohidi, "Measurement and modeling of water content in low temperature hydratemethane and hydrate-natural gas systems," Journal of Chemical and Engineering Data, vol. 56, no. 6, pp. 2932-2935, 2011.

[70] Z. Duan, N. Møller, and J. H. Weare, "An equation of state for the $\mathrm{CH}_{4}-\mathrm{CO}_{2}-\mathrm{H}_{2} \mathrm{O}$ system: II. Mixtures from 50 to $1000^{\circ} \mathrm{C}$ and 0 to 1000 bar," Geochimica et Cosmochimica Acta, vol. 56, no. 7, pp. 2619-2631, 1992.

[71] Z. Duan, N. Møller, and J. H. Weare, "An equation of state for the $\mathrm{CH}_{4}-\mathrm{CO}_{2}-\mathrm{H}_{2} \mathrm{O}$ system: I. Pure systems from 0 to $1000^{\circ} \mathrm{C}$ and 0 to 8000 bar," Geochimica et Cosmochimica Acta, vol. 56, no. 7, pp. 2605-2617, 1992.

[72] M. K. Davie, O. Y. Zatsepina, and B. A. Buffett, "Methane solubility in marine hydrate environments," Marine Geology, vol. 203, no. 1-2, pp. 177-184, 2004.

[73] S. Hashemi, A. Macchi, S. Bergeron, and P. Servio, "Prediction of methane and carbon dioxide solubility in water in the presence of hydrate," Fluid Phase Equilibria, vol. 246, no. 1-2, pp. 131136, 2006.

[74] W. Lu, I. M. Chou, and R. C. Burruss, "Determination of methane concentrations in water in equilibrium with sI methane hydrate in the absence of a vapor phase by in situ Raman spectroscopy," Geochimica et Cosmochimica Acta, vol. 72, no. 2, pp. 412-422, 2008.

[75] P. Servio and P. Englezos, "Measurement of dissolved methane in water in equilibrium with its hydrate," Journal of Chemical and Engineering Data, vol. 47, no. 1, pp. 87-90, 2002.

[76] O. Y. Zatsepina and B. A. Buffett, "Phase equilibrium of gas hydrate: implications for the formation of hydrate in the deep sea floor," Geophysical Research Letters, vol. 24, no. 13, pp. 15671570, 1997.

[77] O. Y. Zatsepina and B. A. Buffett, “Thermodynamic conditions for the stability of gas hydrate in the seafloor," Journal of Geophysical Research B, vol. 103, no. 10, pp. 24127-24139, 1998.

[78] Y. S. Kim, S. K. Ryu, S. O. Yang, and C. S. Lee, "Liquid waterhydrate equilibrium measurements and unified predictions of hydrate-containing phase equilibria for methane, ethane, propane, and their mixtures," Industrial and Engineering Chemistry Research, vol. 42, no. 11, pp. 2409-2414, 2003.

[79] Z. Duan and S. Mao, "A thermodynamic model for calculating methane solubility, density and gas phase composition of methane-bearing aqueous fluids from 273 to $523 \mathrm{~K}$ and from 1 to 2000 bar," Geochimica et Cosmochimica Acta, vol. 70, no. 13, pp. 3369-3386, 2006.

[80] A. Ben-Naim and M. Yaacobi, "Effects of solutes on the strength of hydrophobic interaction and its temperature dependence," Journal of Physical Chemistry, vol. 78, no. 2, pp. 170-175, 1974.

[81] W. F. Claussen and M. F. Polglase, "Solubilities and structures in aqueous aliphatic hydrocarbon solutions," Journal of the American Chemical Society, vol. 74, no. 19, pp. 4817-4819, 1952. 
[82] Z. Duan, N. Møller, J. Greenberg, and J. H. Weare, "The prediction of methane solubility in natural waters to high ionic strength from 0 to $250^{\circ} \mathrm{C}$ and from 0 to 1600 bar," Geochimica et Cosmochimica Acta, vol. 56, no. 4, pp. 1451-1460, 1992.

[83] T. D. O'Sullivan and N. O. Smith, “The solubility and partial molar volume of nitrogen and methane in water and in aqueous sodium chloride from 50 to $125^{\circ} \mathrm{C}$ and 100 to 600 Atm," Journal of Physical Chemistry, vol. 74, no. 7, pp. 1460-1466, 1970.

[84] L. C. Price, "Aqueous solubility of methane at elevated pressures and temperatures," The American Association of Petroleum Geologists bulletin, vol. 63, no. 9, pp. 1527-1533, 1979.

[85] R. C. Sultanov, V. E. Skripka, and A. Y. Namiot, "Solubility of methane in water at high temperatures and pressures," Gazova Promyshlennost, vol. 17, pp. 6-7, 1972 (Russian).

[86] D. A. Wiesenburg and N. L. Guinasso, "Equilibrium solubilities of methane, carbon monoxide, and hydrogen in water and sea water," Journal of Chemical and Engineering Data, vol. 24, no. 4, pp. 356-360, 1979.

[87] S. Yamamoto, J. B. Alcauskas, and T. E. Crozier, "Solubility of methane in distilled water and seawater," Journal of Chemical and Engineering Data, vol. 21, no. 1, pp. 78-80, 1976.

[88] A. Chapoy, A. H. Mohammadi, D. Richon, and B. Tohidi, "Gas solubility measurement and modeling for methane-water and methane-ethane-n-butane-water systems at low temperature conditions," Fluid Phase Equilibria, vol. 220, no. 1, pp. 113-121, 2004.

[89] Y. Shibue, "Vapor pressures of aqueous $\mathrm{NaCl}$ and $\mathrm{CaCl}_{2}$ solutions at elevated temperatures," Fluid Phase Equilibria, vol. 213, no. 1-2, pp. 39-51, 2003.

[90] W. Wagner and A. Pruss, "International equations for the saturation properties of ordinary water substance. Revised according to the international temperature scale of 1990," Journal of Physical and Chemical Reference Data, vol. 22, pp. 783-787, 1993, addendum to Journal of Physical and Chemical Reference Data vol. 16, pp. 893, 1987.

[91] A. H. Mohammadi, A. Chapoy, B. Tohidi, and D. Richon, "A semiempirical approach for estimating the water content of natural gases," Industrial and Engineering Chemistry Research, vol. 43, no. 22, pp. 7137-7147, 2004.

[92] R. Sun, Z. Huang, and Z. Duan, "A new equation of state and Fortran 77 program to calculate vapor-liquid phase equilibria of $\mathrm{CH}_{4}-\mathrm{H}_{2} \mathrm{O}$ system at low temperatures," Computers and Geosciences, vol. 29, no. 10, pp. 1291-1299, 2003.

[93] E. Zebrowski, Fundamentals of Physical Measurement, Wadsworth, Belmont, Calif, USA, 1979.

[94] Gas Processors Association, "Thermodynamic Database Version 2.0," Oklahoma State University, Okla, USA, 1996. 

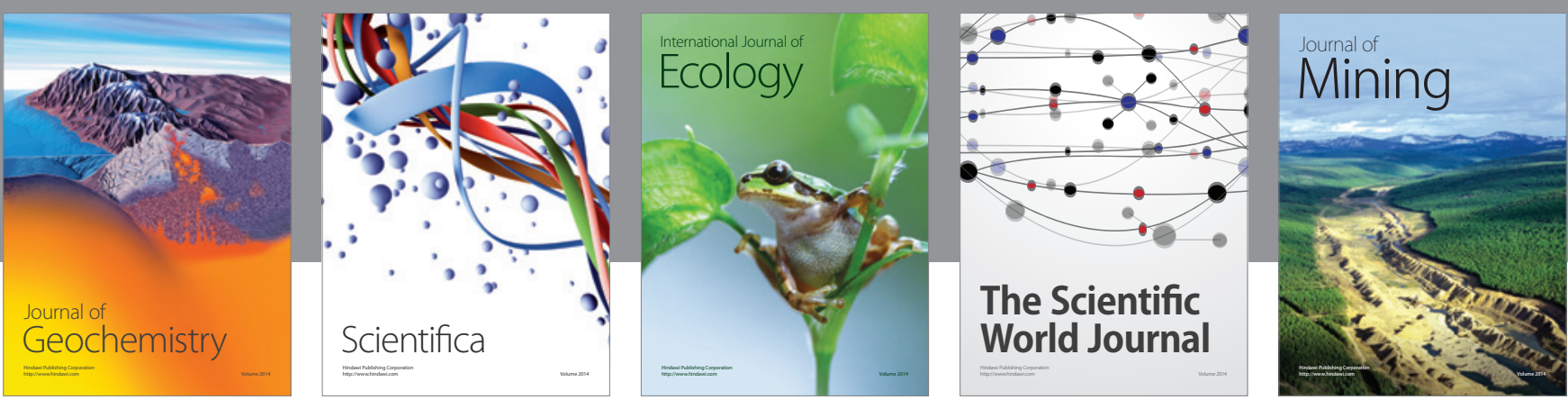

The Scientific World Journal
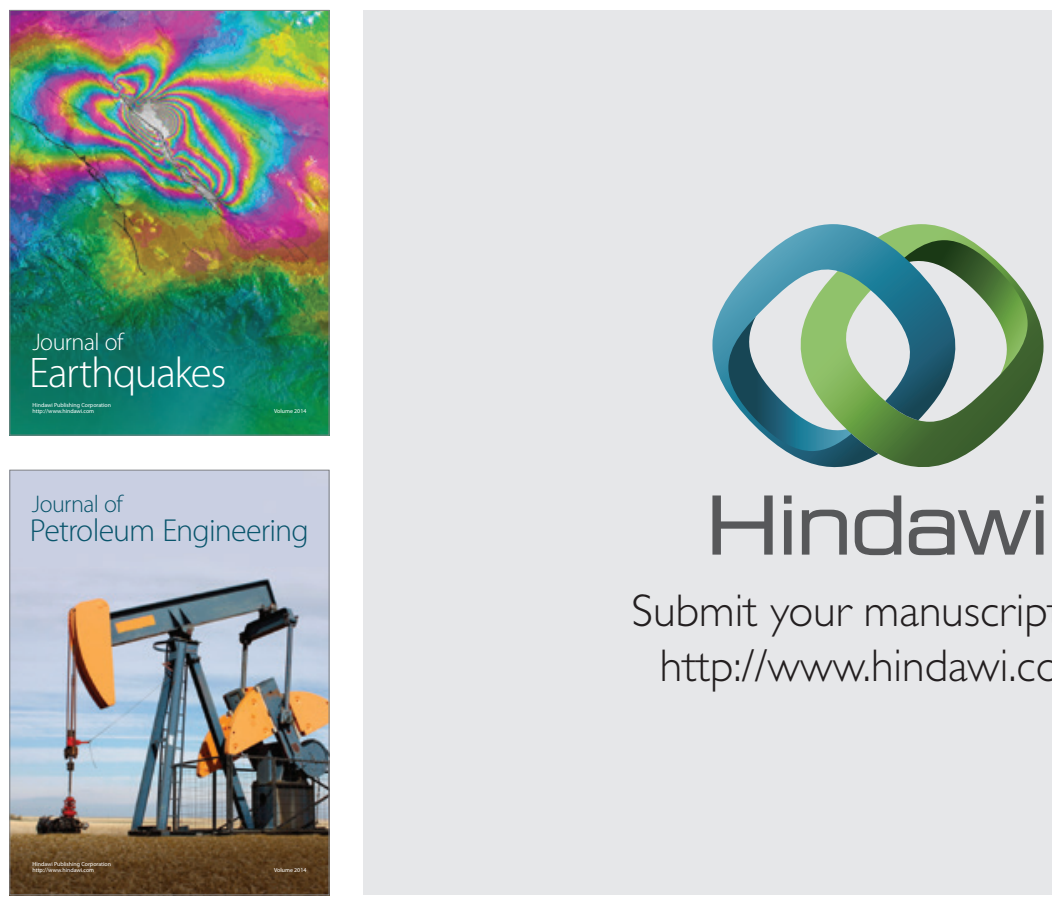

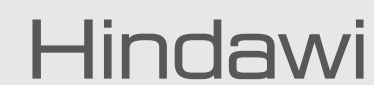

Submit your manuscripts at

http://www.hindawi.com
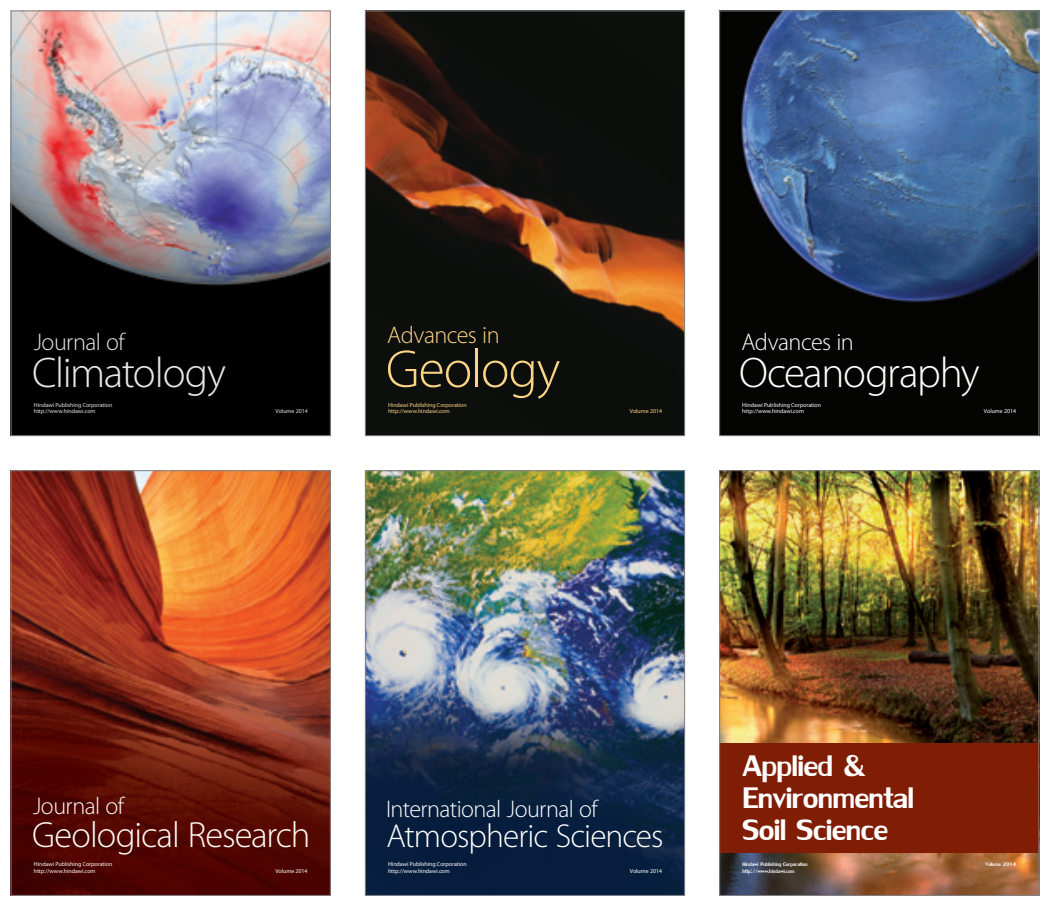
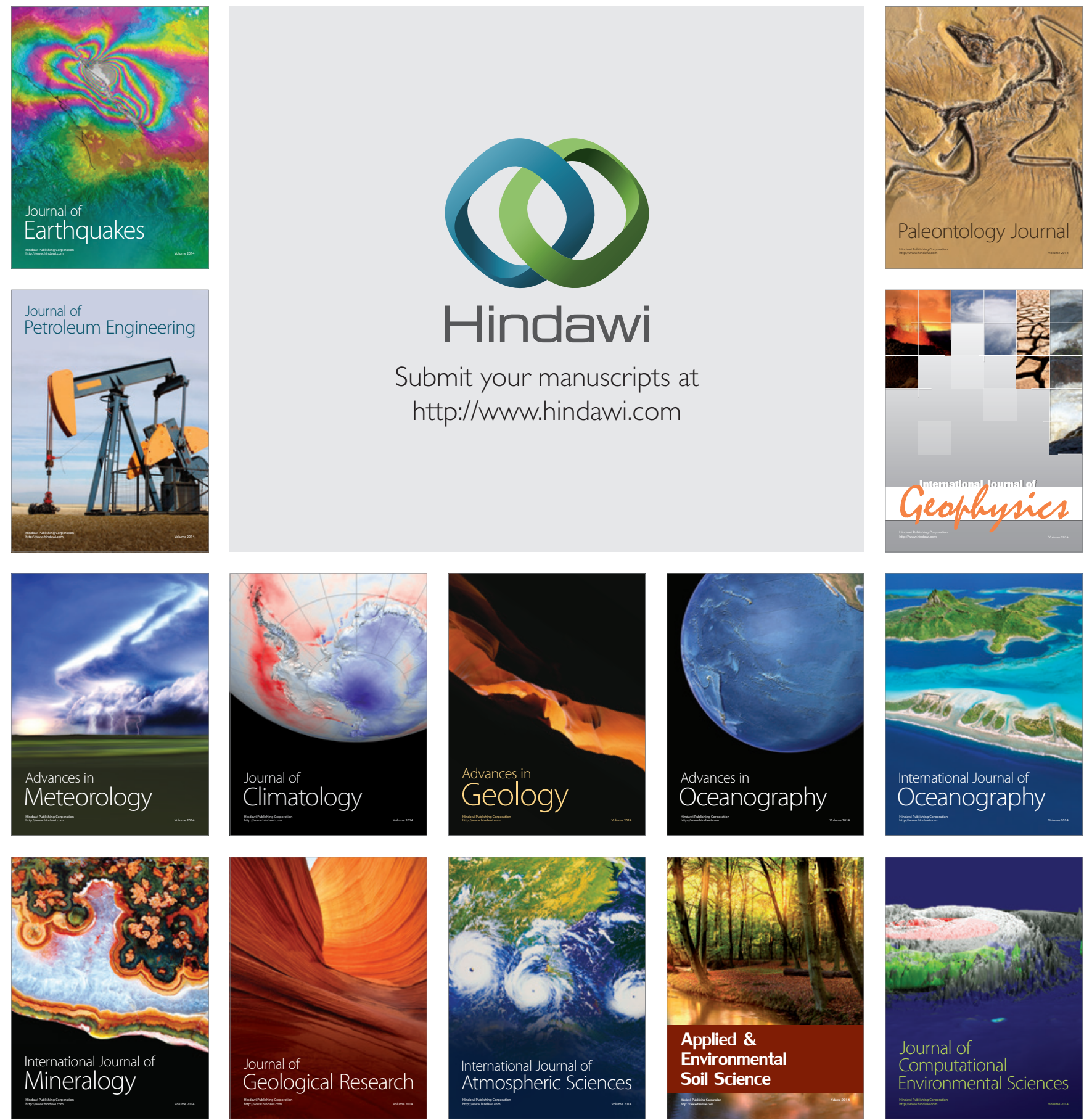